
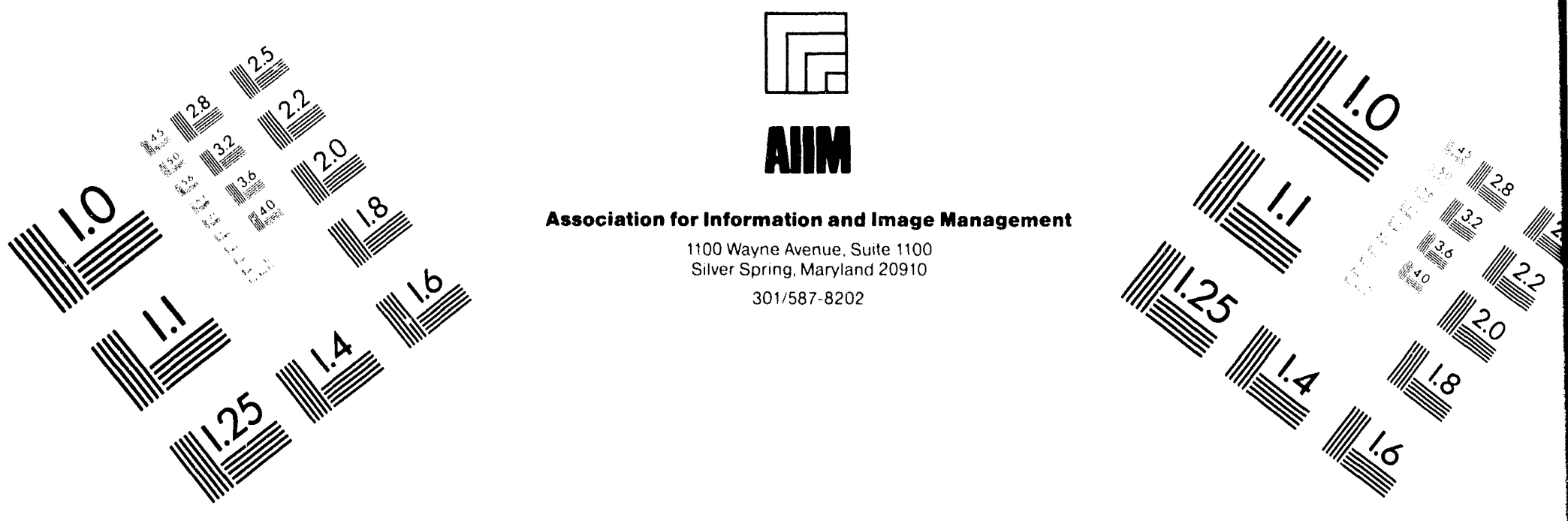

\title{
Centimeter
}

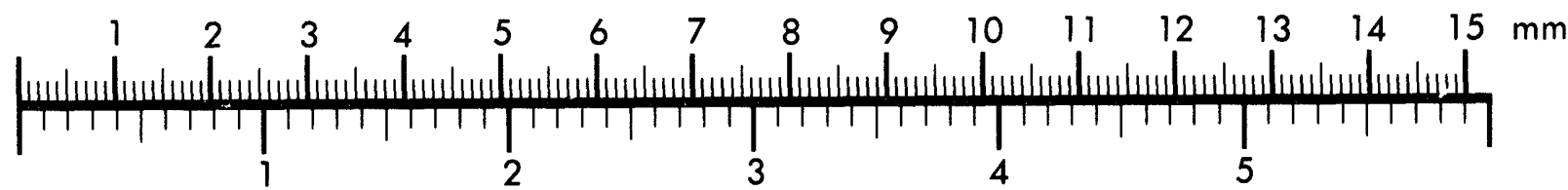
Inches
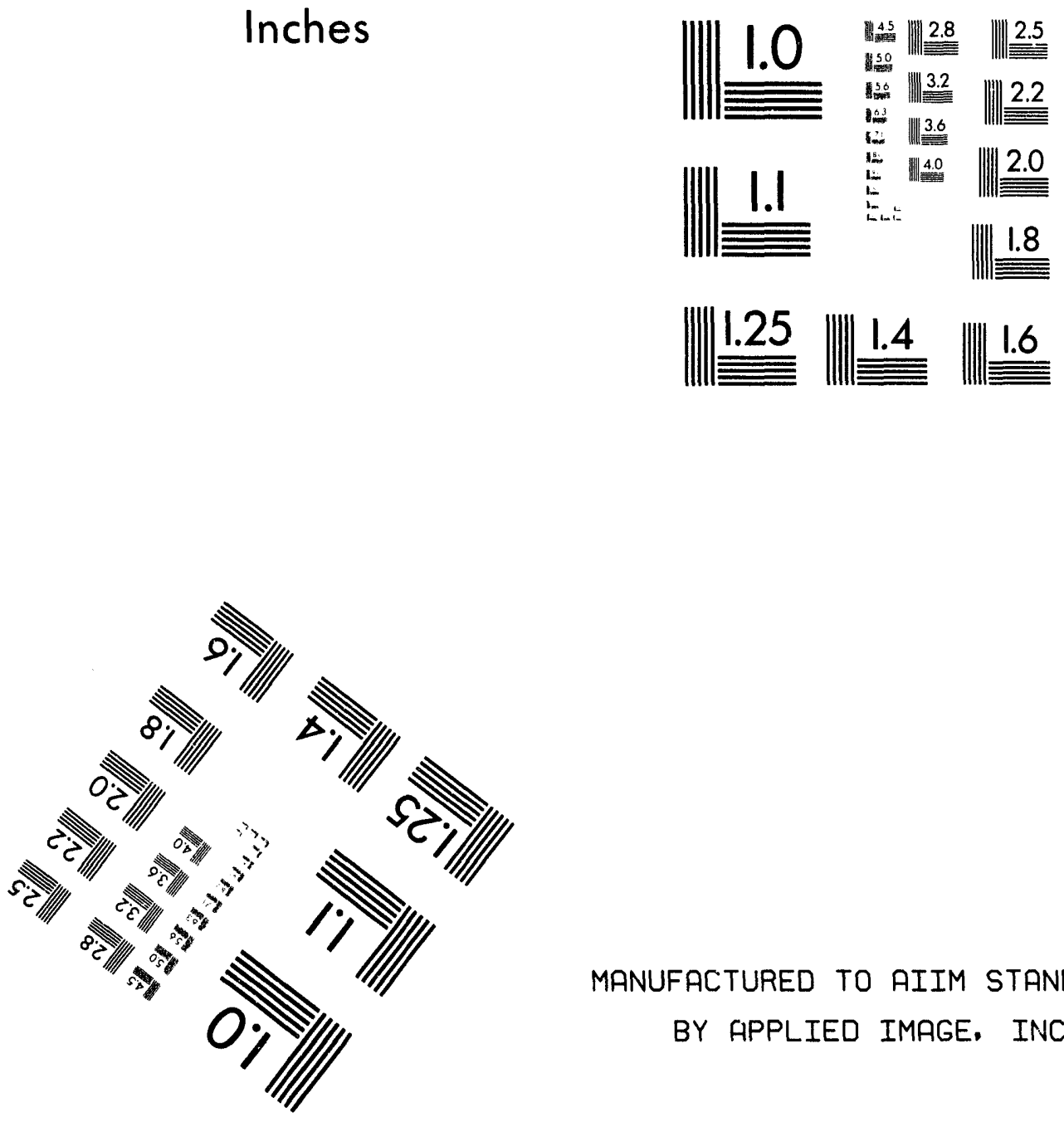

MANUFACTURED TO AIIM STANDARDS BY APPLIED IMAGE, INC.

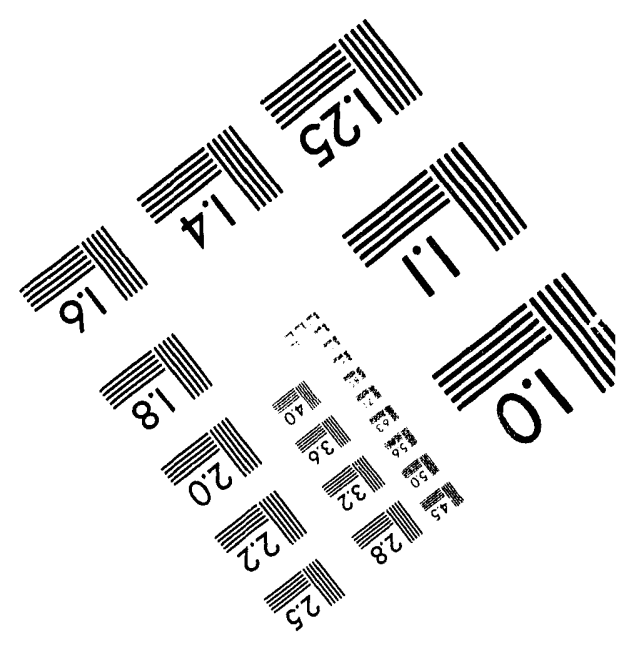



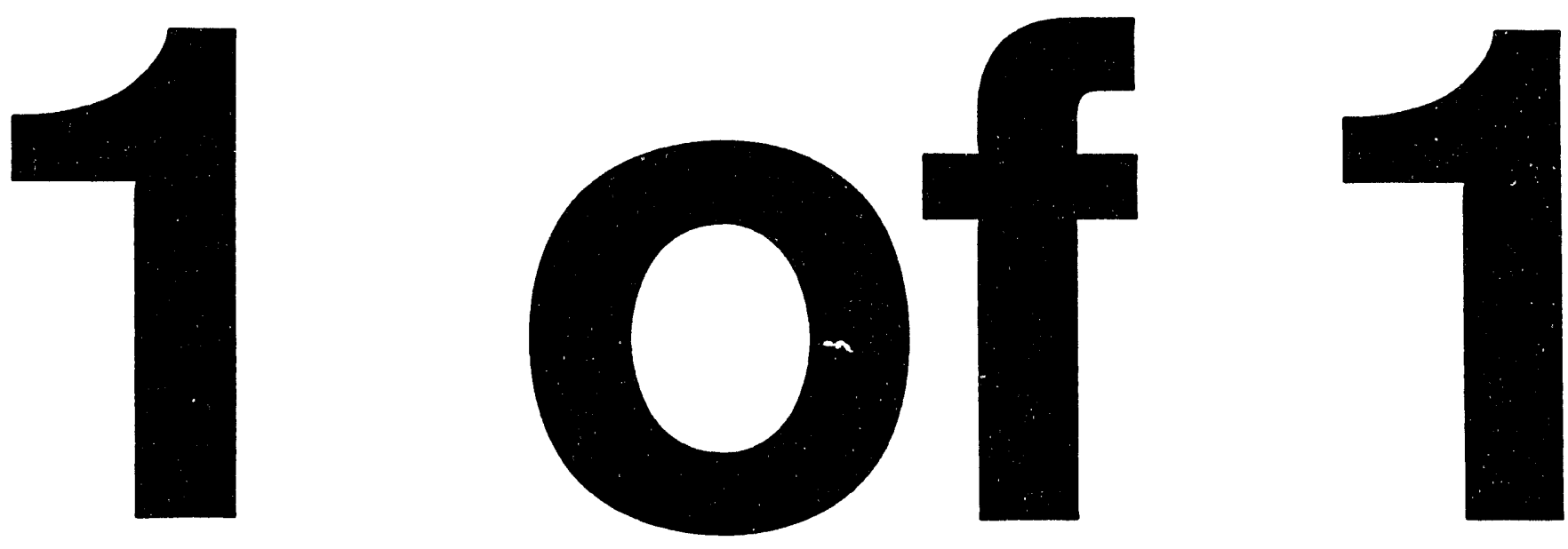

1 
NUREG-1426

Vol. 2

\section{Compilation of Reports from Research Supported by the Materials Engineering Branch, Division of Engineering}

$1991-1993$

Manuscript Completed: May 1994

Date Published: June 1994

Compiled by A. L. Hiser

Materials Engineering Branch

Division of Engineering

Office of Nuclear Regulatory Research

U.S. Nuclear Regulatory Commission

Washington, DC 20555-0001

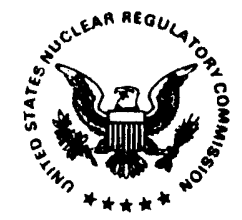


ABSTRACr

\begin{abstract}
Since 1965, the Materials Engineering Branch, Division of Engineering, of the Nuclear Regulatory Commission's Office of Nuclear Regulatory Research, and its predecessors dating back to the Atomic Energy Commission (AEC), has sponsored research programs concerning the integrity of the primary system pressure boundary of light water reactors. The components of concern in these research programs have included the reactor pressure vessel (RPV), steam generators, and the piping. These research programs have covered a broad range of topics, including fracture mechanics analysis and experimental work for RPV and piping applications, inspection method developrnent and qualification, and evaluation of irradiation effects to RPV steels.
\end{abstract}

This report provides as complete a listing as practical of formal technical reports submitted to the NRC by the investigators working on these rescarch programs. This listing includes topical, final and progress reports, and is segmented by topic area. In many cases a report will cover several topics (sucin as in the case of progress reports of multi-faceted programs), but is listed under only one topic. Therefore, in searching for reports on a specific topic, other related topic areas should be checked also. The separate volumes of this report cover the following periods:

Volume 1: 1965 - 1990

Volume 2: 1991 - 1993 


\section{CONTENTS}

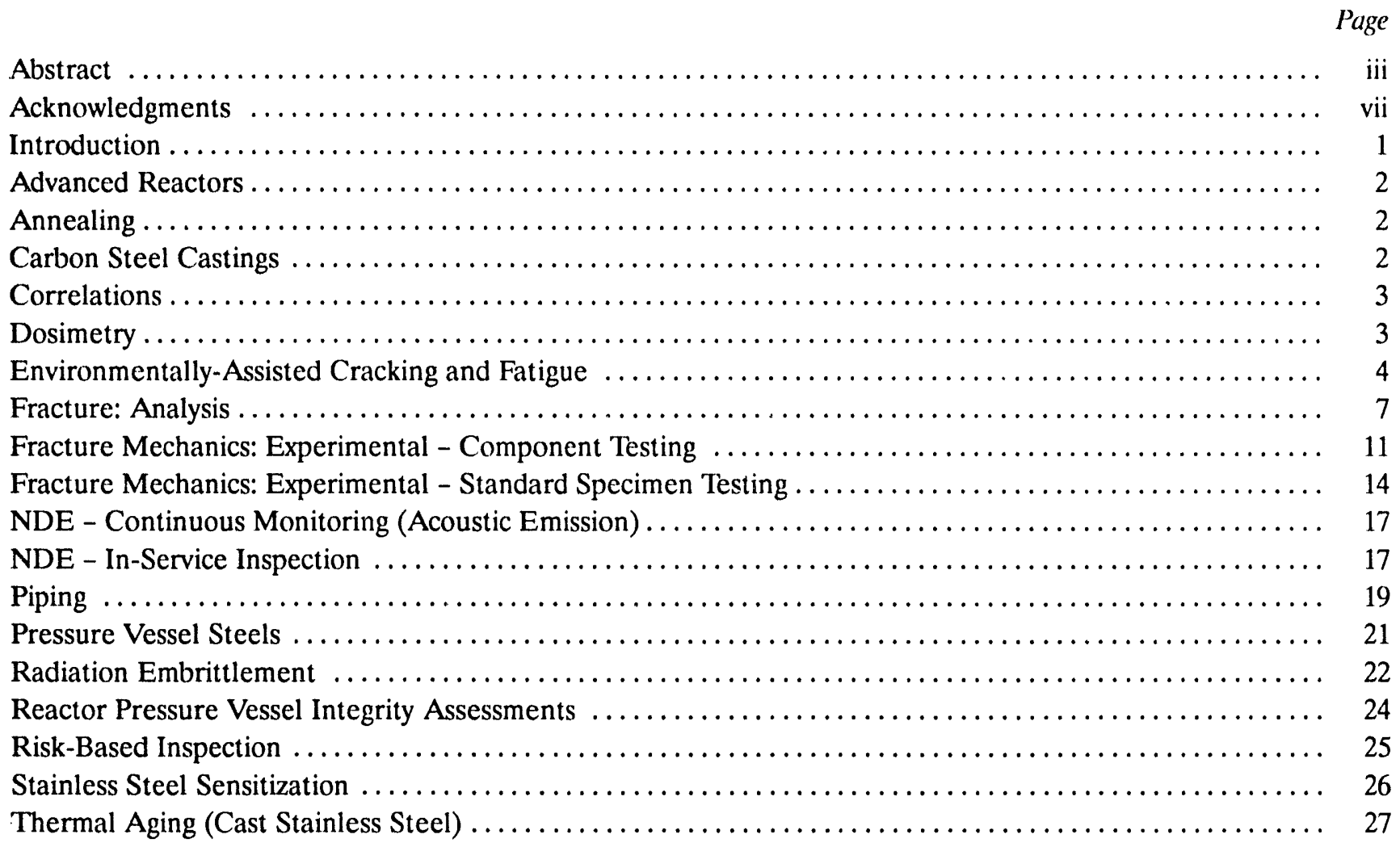




\section{ACKNOWLEDGMENTS}

The assistance of S. Davis in preparing this report is appreciated. 


\section{INTRODUCTION}

Since 1965, the Materials Engineering, Branch, Division of Engineering. of the Nuclear Regulatory Commission's Office of Nuclear Regulatory Research, and its predecessors dating back to the Atomic Energy Commission (AEC), has sponsored research programs concerning the integrity of the primary system pressure boundary of light water reactors. The components of concern in these research programs have included the reactor pressure vessel (RPV), steam generators, and the piping. These research programs have covered a broad range of topics, including fracture mechanics analysis and experimental work for RPV and piping applications, inspection method development and qualification, and evaluation of irradiation effects to RPV steels.

The branch sponsoring these research programs has had various names and affiliations over the years, including the following:

1965-1973 Reactor Vessels Branch, Division of Reactor Development and Technology, U.S. Atomic Energy Commission

1973-1975 Metallurgy and Materials Research Branch, Division of Reactor Safety Research, U.S. Atomic Energy Commission
1975-1981 Metallurgy and Matcrials Rescarch Branch, Division of Reactor Safety Rescarch, U.S. Nuclear Regulatory Commission

1981-1986 Materials Engincering Branch, Division of Engineering 'Technolngy, U.S. Nuclear Regulatory Commission

1986-1993 Materials Engineering Branch, Division of Engineering, U.S. Nuclear Regulatory Commission

This report provides as complete a listing as practical of formal technical reports submitted to the NRC by the investigators working on these research programs. This listing includes topical, final and progress reports, and is segmented by topic area. In many cases a report will cover several topics (such as in the case of progress reports of multi-faceted programs), but is listed under only one topic. Therefore, in searching for reports on a specific topic, other related topic areas should be checked also.

The separate volumes of this report cover the following periods:

Volume 1: $1965-1990$

Volume 2: 1991 - 1993 


\section{Advanced Reactors}

Huddleston, R. L., Oak Ridge National Laboratory, "Pressure Vessel Safety Research for Advanced Reactors. Semiannual Progress Report for December 1991 - March 1992," NUREG/CR-5900, Vol. 1, No. '., U.S. Nuclear Regulatory Commission, Washington, D.C., November 1992.

The NRC sponsored "Pressure Vessel Safety Research for Advanced Reactors" project was initiated at Oak Ridge National Laboratory in December 1992. The objective of the project is to identify and assist NRC in resolving any outstanding safety issues in the materials, fabrication, design, or environmental effects areas for the reactor pressure vessel for the advanced reactors such that these issues do not negatively impact the design certification process. The major output from this project during the first year will be white papers summarizing the unresolved issues with recommended plans for their resolution. The project will address two advanced evolutionary, two advanced passive, and four advanced reactor systems. During this first report period progress included: development of a detailed technical approach to be followed in identifying and resolving the issues; identification of documents containing information needed for the assessments and requesting these through official channels; identification of relevant design code and regulatory documents and acquiring those which are not locally available; development of a listing of information needed from the reactor manufacturers in preparation for visiting the manufacturers to hold discussions with their technical personnel; development of a preliminary outline for the white papers; and initiation of document reviews.

Huddleston, R. L. and Swindeman, R. W., Oak Ridge National Laboratory, "Materials and Design Bases Issues in ASME Code Case N-47," NUREG/ CR-5955, U.S. Nuclear Regulatory Commission, Washington, D.C., April 1993.

A preliminary evaluation of the design bases (principally ASME Code Case N-47) was conducted for design and operation of reactors at elevated temperatures where the time-dependent effects of creep, creep-fatigue, and creep ratcheting are significant. Areas where Code rules or regulatory guides may be lacking or inadequate to ensure the operation over the expected life cycles for the next-generation advanced high-temperature reactor systems, with designs to be certified by the U.S. Nuclear Regulatory Commission, have been identified as unresolved issues. 'Twenty-two unresolved issues were identi- fied and brief scoping plans developed for resolving these issues.

\section{Annealing}

Cole, N. M. and Friderichs, T., MPR Associates, Inc., "Report on Anncaling of the Novovoronezh Unit 3 Reactor Vessel in the USSR," NUREG/CR-5760, U.S. Nuclear Regulatory Commission, Washington, D.C., July 1991.

A U.S. delegation attended the thermal anncaling operation of the Novovoronezh Unit 3 reactor vessel in the USSR to cvaluate the Soviet reactor vessel annealing technology and to determine its applicability to PWR reactors in the U.S. Operations observed and described in this report include reactor vessel sample cutting, preparations for annealing, installation of annealing apparatus, and initial heatup of the reactor vessel. The annealing operation witnessed has been developed to a routine operation and appears applicable to U.S. PWRs. Key areas requiring further work to confirm applicability to U.S. reactors are discussed.

\section{Carbon Steel Castings}

Nanstad, R. K., et al., Oak Ridge National Laboratory, "Effects of Nonstandard Heat Treatment Temperatures on Tensile and Charpy Impact Properties of Carbon-Stcel Casting Repair Welds," NUREG/ CR-5972, U.S. Nuclear Regulatory Commission, Washington, D.C., April 1993.

Carbon steel castings are used for a number of different components in nuclear power plants, including valve bodies and bonnets. Components are often repaired by welding processes, and both welded components and the repair welds are subjected to a variety of postweld heat treatments (PWH'T) with temperatures as high as $899^{\circ} \mathrm{C}$ $\left(1650^{\circ} \mathrm{F}\right)$, well above the normal 593 to $677^{\circ} \mathrm{C}$ $\left(1100\right.$ to $\left.1250^{\circ} \mathrm{F}\right)$ temperature range. The temperatures noted are above the Al transformation temperature for the materials used for these components. A test program was conducted to investigate the potential effects of such "nonstandard" PWHTs on mechanical properties of carbon steel casting welds. Four weldments were fabricated, two each with the shielded-metal-arc (SMA) and flux-cored-arc (FCA) processes, with a high-carbon and low-carbon filler metal in cach case. All four welds were sectioned and given simulated PWH'Is at temperatures from 621 to $899^{\circ} \mathrm{C}\left(1150\right.$ to $1650^{\circ} \mathrm{F}$ ) in increments of $56^{\circ} \mathrm{C}$ $\left.(10)^{\circ} \mathrm{F}\right)$ and for times of $5,10,20$, and $40 \mathrm{~h}$ at each temperature. Hardness, tensile, and Charpy V-notch (CVN) impact tests were conducted for 
the as-wclded and heat-treated conditions. Results were plotted versus a time-temperature relationship (tempering parameter) to enable a more direct comparison of the effects of the various PWHT conditions. Heat treatments at 621 and $677^{\circ} \mathrm{C}\left(1150\right.$ and $\left.1250^{\circ} \mathrm{F}\right)$ gave results amenable to prediction, and regression analyses are presented for those conditions. Heat treatments at 732 to $899^{\circ} \mathrm{C}\left(1350\right.$ to $\left.1650^{\circ} \mathrm{F}\right)$, however, resulted in substantial changes in mechanical properties of these SMA and FCA welds, with the changes not amenable to prediction and highly dependent on the weld metal. Heat treatments in that temperature range should not be applied to these materials without prior qualification for the intended use.

\section{Correlations}

Eason, E. D., et al., Modeling \& Computer Services, "Multivariable Modeling of Pressure Vessel and Piping J-R Data," NUREG/CR-5729, U.S. Nuclear Regulatory Commission, Washington, D.C., May 1991.

Multivariable models were developed for predicting J-R curves from available data, such as material chemistry, radiation exposure, temperature, and Charpy V-notch energy. The present work involved collection of public test data, application of advanced pattern recognition tools, and calibration of improved multivariable models. Separate models were fitted for different material groups, including RPV welds, Linde 80 welds, RPV base metals, piping welds, piping base metals, and the combined database. Three different types of models were developed, involving different combinations of variables that might be available for applications: a Charpy model, a preirradiation Charpy model, and a copper-fluence model. In general, the best results were obtained with the preirradiation Charpy model. The copper-fluence model is recommended only if Charpy data are unavailable, and then only for Linde 80 welds. Relatively good fits were obtained, capable of predicting the values of $\mathrm{J}$ for pressure vessel steels to within standard deviation of $13-18 \%$ over the range of test data. The models were qualified for predictive purposes by demonstrating their ability to predict validation data not used for fitting.

\section{Dosimetry}

McElroy, W. N., et al., Pacific Northwest Laboratory, "LWR Pressure Vessel Surveillance Dosimetry Improvement Program. PSF Startup Experiments,"
NUREG/CR-3320 Vol. 2, U.S. Nuclear Regulatory Commission, Washington, D.C., July 1992.

The metallurgical irradiation experiment at the Oak Ridge Research Reactor Poolside Facility (ORR-PSF) is one of the series of benchmark experiments in the framework of the Light Water Reactor Pressure Vessel Surveillance Dosimetry Improvement Program (LWR-PV-SIDIP). The goal of this program is to test, against wellestablished benchmarks, the methodologies and data bases that are used to predict the irradiation embrittlement and fracture toughness of pressure vessel and support structure stecls. 'The prediction methodology includes procedures for neutron physics calculations, dosimetry and spectrum adjustment methods, metallurgical tests, and damage correlations. The benchmark experiments serve to validate, improve, and standardize these procedures. The results of this program are implemented in a set of ASTM Standards on pressure vessel surveillance procedures. These, in turn, may be used as guides for the nuclear industry and for the Nuclear Regulatory Commission (NRC). To serve as a benchmark, a very careful characterization of the ORR-PSF experiment is necessary, both in terms of neutron flux-fluence spectra and of metallurgical test results. Statistically determined uncertainties must be given in terms of variances and covariances to make comparisons between predictions and experimental results meaningful. Detailed descriptions of the PSF physics-dosimetry startup experiments and their results are reported.

Williams, M. L., Louisiana State University, et al., "Transport Calculations of Neutron Transmission Through Steel Using ENDF/B-V, Revised ENDF/ B-V, and ENDF/B-VI Iron Evaluations," NUREG/ CR-5648, U.S. Nuclear Regulatory Commission, Washington, D.C., April 1991.

The ENDF/B-VI evaluated nuclear data file has been recently released by the U.S. National Nuclear Data Center during 1990. Among the most eagerly awaited new cross-section evaluations in this data collection are those for the natural iron isotopes, due to their importance in nuclear systems analysis and because the previous ENDF/B data (version V, which was released in 1979) are known to underestimate the transmission of fast neutrons through steel structures such as reactor pressure vessels and radiation shielding. In this paper, a comparison is made of results obtained from neutron transport calculations performed with these two ENDF/B versions (V and VI) of iron data as well as an intermediate, revised version $V$ evaluation that was proposed in 1986. Several different response parameters that are 
sensitive to high energy neutrons are examined, for a variety of geometrical configurations and source spectra. It is found that the two newer iron evaluations substantially increase the transmission of high energy neutrons through steel components with an incident fission spectrum source. Preliminary estimates indicate that the version VI iron evaluation will considerably improve the agreement between calculations and experimental dosimeter measurements used in light water reactor pressure vessel fluence analysis. The calculated leakage spectrum of D-T fusion neutrons from an iron sphere is also improved for energies above $4 \mathrm{MeV}$, but large discrepancies with the measured spectrum are still observed at lower energies.

\section{Environmentally-Assisted Cracking and Fatigue}

Chung, H. M., et al., Argonne National Laboratory, "Environmentally Assisted Cracking in Light Water Reactors. Semiannual Report, April-September 1990," NUREG/CR-4667, Vol. 11, U.S. Nuclear Regulatory Commission, Washington, D.C., May 1991.

This report summarizes work performed by Argonne National Laboratory on environmentally assisted cracking in light water reactors during the six months from April 1990 to September 1990. Crack-growth-rate (CGR) iests were performed on a composite A533-Gr. B/Inconel-182 specimen in which a stress corrosion crack in the Inconel-182 weld metal penetrated and grew into the A533-Gr. B steel. CGR tests were also conducted on conventional (nonplated) and $\mathrm{Ni}$ - or Au-plated A533-Gr. B specimens. CGR data on the A533-Gr. B specimens were compared with the fatigue crack reference curves in the ASME Boiler and Pressure Vessel Code, Section XI, Appendix A. High- and commercial-purity (HP) and (CP), respectively, specimens of Type $304 \mathrm{SS}$ from BWR absorber-rod tubes, irradiated during service to fluence levels of $6 \times 10^{20}-2 \times 10^{21} \mathrm{n} / \mathrm{cm}^{2}$ $(\mathrm{E}>1 \mathrm{MeV}$ ) in two reactors, were examined by Auger electron spectroscopy to characterize irradiation-induced grain boundary segregation and depletion of alloying and impurity elements, which have been associated with irradiation-assisted stress corrosion cracking of the steel. Intergranular fracture surfaces in high-fluence $\mathrm{CP}$ material were characterized by relatively high levels of Si, P, and Ni segregation. Segregation of the impurity elements and intergranular failure in the HP material were negligible for a similar fluence level. However, grain boundary depletion of $\mathrm{Cr}$ was more significant in high-purity material than in CP matcrial, which indicates that irradiationinduced segregation of impurity elements and depletion of alloying elements are interdependent.

Chung, H. M., et al., Argonne National Laboratory, "Environmentally Assisted Cracking in Light Water Reactors. Semiannual Report, October 1991 - March 1992," NUREG/CR-4667, Vol. 14, U.S. Nuclear Regulatory Commission, Washington, D.C., August 1992.

This report summarizes work performed by Argonne National Laboratory on fatigue and environmentally assisted cracking in light water reactors during the six months from October 1991 through March 1992. Topics that have been investigated during this period include: (1) fatigue and stress corrosion cracking of low-alloy steel used in piping and in steam generator and reactor pressure vessels; (2) radiation-induced segregation and irradiationassisted SCC of Type 304 SS after accumulation of relatively high fluence; and (3) update of a crack growth data base for austenitic and ferritic steels in high-temperature water. Existing data on fatigue of low-alloy steel in LWR environments have been reviewed. Based on fracture-mechanics models and engineering judgement, interim fatigue design curves are being developed that are consistent with available fatigue-life data. Microchemical and microstructural changes in high- and commercialpurity Type 304 SS specimens from control-blade absorber tubes and a control-blade sheath from operating BWRs were studied by Auger electron spectroscopy and scanning electron microscopy. Slow-strain-rate-tensile tests were conducted on irradiated specimens in air and in simulated BWR water at $289^{\circ} \mathrm{C}$. Crack growth data on fracture-mechanics specimens of austenitic and ferritic steels in simulated BWR water, developed in this program over the past 8 years, are compiled into a data base along with references that contain details of test methods, material compositions, metallographic information, and comparisons of data with predictions of Section XI of the ASME Code.

Chung, H. M., et al., Argonne National Laboratory, "Environmentally Assisted Cracking in Light Water Reactors. Semiannual Report, October 1992 - March 1993," NUREG CR-4667, Vol. 16, U.S. Nuclear Regulatory Commission, Washington, D.C., September 1993.

This report summarizes work performed by Argonne National Laboratory on fatigue and environmentally assisted cracking (EAC) in light water reactors (LWRs) during the six months from October 1992 through March 1993. Fatigue and EAC of piping, pressure vessels, and core components in LWRs are important concerns as 
extended reactor lifetimes are envisaged. Topies that have been investigated include (1) fatigue of low-alloy stecl used in piping, steam generators, and reactor pressure vessels, (2) EAC of cast stainless steels (SSs), (3) radiation-induced segregation and irradiation-assisted stress corrosion cracking of Type 304 SS after accumulation of relatively high fluence, and (4) EAC of low-alloy steels. Fatigue tests were conducted on mediumsulfur-content A106-Gr. B piping and A533-Gr. $B$ pressure vessel stecls in simulated PWR water and in air. Additional crack growth data were obtained on fracture-mechanics specimens of cast austenitic SSs in the as-received and thermally aged conditions and chromium-nickel-plated A533-Gr. B steel in simulated boiling-water reactor (BWR) water at $289^{\circ} \mathrm{C}$. The data were compared with predictions based on crack growth correlations for ferritic steels in oxygenated water and correlations for wrought austenitic SS in oxygenated water developed at ANL and rates in air from Section XI of the ASME Code. Microchemical and microstructural changes in high- and commercial-purity Type 304 SS specimens from control-blade absorber tubes and a control-blade sheath from operating BWRs were studied by Auger electron spectroscopy and scanning electron microscopy.

Kassner, T. F., et al., Argonne National Laboratory. "Environmentally Assisted Cracking in Light Water Reactors. Semiannual Report, April-September 1989," NUREG/CR-4667, Vol. 9, U.S. Nuclear Regulatory Commission, Washington, D.C., March 1991.

This report summarizes work performed by Argonne National Laboratory on environmentally assisted cracking in light water reactors during the six months from April 1989 to September 1989. Topics that were investigated include (1) stress corrosion cracking (SCC) of A533-Gr. B steel in simulated boiling-water-reactor environments, (2) SCC of Types 347 and CF-3 cast duplex stainless steel (SS), and (3) effects of heatto-heat variation on SCC of Type 304 SS. Crackgrowth-rate (CGR) tests were performed on conventional (non-plated) and nickel-or goldplated A533-Gr. B specimens to provide insight into whether the surface layer on the low-alloy steel, either oxide corrosion products or a noble metal, influences the overall SCC process. CGR tests were also conducted on specimens of Type 347 SS with different heat-treatments, and a specimen of CF-3 cast SS with a ferrite content of $15.6 \%$. CGR data on these specimens were compared with reference fatigue crack growth curves in the ASME Boiler and Pressure Vessel Code, Section XI, Appendix A. The influence of approx- imately $1.0 \mathrm{ppm}$ of $\mathrm{CuCl}$ in deoxygenated water on the SCC susceptibility of 'Types $316 \mathrm{NG}$ and 347 SS and A533-Gr. B and A 106-Gr. B ferritic steels was determined in constant-cxtension-rate tensile (CERI) tests at $200 \mathrm{C}^{\circ}$. 'The ('ER'T results indicated that the alternative SSs were considerably more resistant to SCC than is sensitized Type 304 SS. The low-alloy ferritic steels exhibited only ductile fracture in this environment.

Kassner, T. F., et al., Argonne National Laboratory, "Environmentally Assisted Cracking in Light Water Reactors. Semiannual Report, April-September 1991," NUREG/CR-4667, Vol. 13, U.S. Nuclear Regulatory Commission. Washington, D.C., March 1992.

This report summarizes work performed by Argonne National Laboratory on fatigue and environmentally assisted cracking in light water reactors during the six months from April 1991 through Scptember 1991. Topics that have been investigated during this period include: (1) fatigue and stress corrosion cracking (SCC) of low-alloy stecl used in piping and in steam generator and reactor pressure vessels; (2) role of chromate and sulfate in simulated boiling water reactor (BWR) water on $\mathrm{SCC}$ of sensitized Type 304 SS; and (3) radiation-induced segregation (RIS) and irradiation-assisted SCC of Type 304 SS after accumulation of relatively high fluence. Fatigue data were obtained on medium-Scontent A533-Gr. B and A106-Gr. B stecls in highpurity, (HP) deoxygenated water, in simulated pressurized water reactor (PWR) water, and in air. Crack-growth-rates (CGRs) of composite specimens of A533-Gr. B/Inconel-182/Inconcl-M (plated with nickel) and homogeneous specimens of A533-Gr. B were determined under smallamplitude cyclic loading in HP water with $\sim 300 \mathrm{ppb}$ dissolved oxygen. CGR tests on sensitized Type 304 SS indicate that low chromate concentrations in BWR water (25-35 ppb) may actually have a beneficial effect on SCC if the sulfate concentration isbelow a critical level. Microchemical and microstructural changes in HP and commercial-purity iype 304 SS specimens from control-blade absorber tubes used in two operating BWRs were studied by Auger electron spectroscopy and scanning electron microscopy, and slow-strain-rate-tensile tests were conducted on tubular specimens in air and in simulated BWR water at $289^{\circ} \mathrm{C}$.

Majumdar, S. and Chopra, O. K., Argonne National Laboratory, "Interim Fatigue Design Curves for Carbon, low-alloy, and Austenitic Stainless Steels in LWR Environments," NUREG/CR-5999, U.S. Nuclear Regulatory Commission, Washington, D.C., April 1993.

Existing data in the literature on fatigue of carbon, low-alloy, and austenitic stainless steels in 
LWR environments are reviewed. It is found that both temperature and dissolved-oxygen concentration in water significantly affect fa.igue life. At the very low dissolved-oxygen levels characteristic of pressurized water reactors and boiling water reactors with hydrogen-water chemistry, environmental effects on fatigue life are modest. However, at higher dissolved-oxygen levels ( $\geq 100 \mathrm{ppb}$ ), significant reductions in fatigue life can occur. The susceptibility of carbon and low-alloy steels to reduced faticue life is strongly related to sulfur concentration. Although the fatigue lives of austenitic stainless steels may be reduced, the reductions are much smaller than those observed in high-sulfur carbon and low-alloy steels. In oxygenated water, fatigue life depends strongly on strain rate. Interim fatigue design curves are proposed that take into account temperature, dissolved-oxygen level in the water, the sulfur level in the steel, and strain rate. Design curves for carbon and low-alloy steels for lives up to $10^{8}$ cycles are also proposed.

Ruther, W. E., et al., Argonne National Laboratory, "Environmentally Assisted Cracking in Light Water Reactors. Semiannual Report, October 1989 - March 1990," NUREG/CR-4667, Vol. 10, U.S. Nuclear Regulatory Commission, Washington, D.C., March 1991.

This report summarizes work performed by Argonne National Laboratory on environmentally assisted cracking in light water reactors during the six months from October 1989 to March 1990. Low-cycle fatigue iests were performed on Type $316 \mathrm{NG}$ SS to better understand the effects of cyclic strain range, frequency, and temperature on fatigue life in air and in simulated BWR water, and to assess the degree of conservatism in the ASME Code Section III fatigue design curves. Fracture mechanics crack-growth-rate tests wer: carried out on a composite specimen of A533-Gr. B/Inconel-182/Inconel-600, plated with nickel, to establish whether a transgranular crack will initiate in the ferritic steel from an intergranular crack in the Inconel-182 weld metal at low stress intensity associated with crack growth in the Inconel-182 weld metal. Irradiated stainless steels from absorber-rod tubes, control-rod cladding, and flux thimbles of severa! BWRS and PWRS were obtained to investigate the nature and extent of radiation-induced segregation in the steels and correlate it with susceptibility to intergranular failure in the materials. Specimens have been prepared for Auger electror spectroscopy analyses of segregation of alloying elements on intergranular fracture surfaces.
Ruther, W. E., et al., Argonne National Laboratory, "Environmentally Assisted Cracking in Light Water Reactors. Semiannual Report, April-September 1992," NUREG/CR-4667, Vol. 15, U.S. Nuclear Regulatory Commission, Washington, D.C., June 1993.

This report summarizes work performed by Argonne National Laboratory on fatigue and environmentally assisted cracking (EAC) in light water reactors (LWRs) during the six months from April 1992 to Scptember 1992. Topics that have been investigated include: (1) fatigue and stress corrosion cracking (SCC) of low-alloy stce! used in piping, steam generators, and reactor pressure vessels; (2) EAC of cast stainless steels (SSs); and (3) rarliation-induced segregation and irradiation-assisted SCC of Type 304 SS after accumulation of relatively high fluence. Data on fatigue of low-alloy steel in LWR environments have been reviewed. Based on fracturemechanics models and engineering judgment, interim fatigue design curves were developed that are consistent with available fatigue-life data. Crack growth data were obtained on fracture-mechanics specimens of A533-Gr. B and A106-Gr. $B$ ferritic steels and on cast austenitic SSs in the as-received and thermally aged conditions in simulated BWR water at $289^{\circ} \mathrm{C}$. The data were compared with predictions based on crack growth correlations for ferritic steels in oxygenated water and correlations for wrought austenitic SS in oxygenated water developed at ANL and rates in air from Section XI of the ASME Code. Microchemical and microstructural changes in high- and commercial-purity Type 304 SS specimens from control-blade absorber tubes and a control-blade sheath frum operating BWRs were studied by Auger electron spectroscopy and scanning elcctron microscopy. Slow-strain-rate-tensile tests were conducted on irradiated specimens in air and simulated BWR water.

Shack, W. J., et al., Argonne National Laboratory, "Environmentally Assisted Cracking in Light Water Reactors. Semiannual Report, October 1990 - March 1991,"NUREG/CR-4667, Vol. 12, U.S. Nuclear Regulatory Commission, Washington, D.C., August 1991.

This report summarizes work performed by Argonne National Laboratnry on environmentally assisted cracking in light water reactors during the six months from October 1990 to March 1991. Fatigue life of A533-Gr. B pressure vessel stecl was studied in high-purity (HP) deoxygenated water, in simulated PWR water, and in air. Fatigue data are compared with the design curve in Section III Appendix A of the ASME Boiler and Pressure Vessel Code. Equations in Section XI of the ASME Boiler and Pressure Vessel Code that 
relate crack growth rates (CGRs) of ferritic steels to loading parameters have been modified to incorporate CGR data that we recently acquired at high load ratios. The effect of water flow rate on the SCC behavior of Type 316NG stainless steel (SS) was investigated in fracture-mechanics CGR tests in HP oxygenated water at $289^{\circ} \mathrm{C}$. Corrosion fatigue curves for austenitic SS in Section XI of the ASME Boiler and Pressure Vessel Code have been modified to be more consistent with SCC data in simulated LWR environments at high load ratios. High- and commercial-purity (CP) specimens of Type 304 SS from BWR absorber-rod tubes, irradiated during service in two reactors to fluence levels of $1.4-2 \times 10^{21} \mathrm{n} / \mathrm{cm}^{2}(\mathrm{E}>1 \mathrm{MeV})$, were examined by Auger electron spectroscopy to characterize irradiation-induced grain boundary segregation and depletion of alloying and impurity elements, which have been associated with irradiation-assisted SCC of the steel. Slow-strainrate tensile tests have been conducted in air and in simulated BWR water on specimens obtained from the irradiated CP Type 304 SS absorber-rod tubes.

\section{Fracture: Analysis}

Bass, B. R., et al., Oak Ridge National Laboratory, "Constraint Effects on Fracture Toughness for Circumferentially Oriented Cracks in Reactor Pressure Vessels," NUREG/CR-6008, U.S. Nuclear Reguiatory Commission, Washington, D.C., August 1992.

Pressurized-thermal-shock (PTS) loading produces biaxial stress fields in a reactor pressure vessel (RPV) wall with one of the principal stresses aligned parallel to postulated surface cracks in either longitudinal or circumferential welds. The limited quantity of existing biaxial test data suggest a significant decrease of fracture toughness under out-of-plane (i.e., parallel to the crack (ront) biaxial loading conditions when compared with toughness values obtained under uniaxial conditions. Any increase in crack-tip constraint resulting from these out-of-plane biaxial stresses would act in opposition to the in-plane constraint relaxation that has been previously demonstrated for shallow cracks. Consequently, understanding of both in-plane and out-of-plane crack-tip constraint effects is necessary to a refined analysis of fracture initiation from shallow cracks under PTS transient loading. This report is the second in a series investigating the potential impact of far-field out-of-plane stresses and strains on fracture initiation toughness. Selected fracture prediction models, previously validated for small-scale fracture specimens under nearly plane st rain conditions, were applied to additional large-seale data with the objective of validating models in the plane stress-t(o-plane strain domain before applying them to positive out-of-plane strain cunditions. The general finding was that applications of the models resulted in predictions of fracture behavior that conflicted with existing experimental data considered relevant to the problem. Because of the conflicting results, it is apparent that testing of RPV stecls is required: (1) to determine the magnitude of out-of-ple ne biaxial loading effects on fracture toughness; and (2) to provicie a basis for development of predictive models. This course of action is riecessary to support a refined treatment of in-plane and outof-plane constraint effects in PTS analysis. Proposed in this report are critcria for a biaxial specimen that would form the basis of a testing program designed to provide data to explain differences between theoretical predictions and measured material behavior. Results of design studies on the biaxial specimen will be presented in a future report from the Heavy-Section Stecl Technology Program.

Bass, B. R., et al., Oak Ridge National Laboratory, "CSNI Project for Fracture Analyses of Large-Scale International Reference Experiments (Project FALSIRE)," NUREG/CR-5997, U.S. Nuclear Regulatory Commission, Washington, D.C., June 1993.

This report summarizes the recently completed Phase I of the Project for Fracture Analysis of large-scale International Reference Experiments (Project FALSIRE). Project FALSIRE was created by the Fracture Assessment Group (FAG) of Principal Working Group No. 3 (PWG/3) of the Organization for Economic Cooperation and Development (OECD)/Nuclear Energy Agency's (NEA's) Committee on the Safety of Nuclear Installations (CSNI). Motivation for the project was derived from recognition by the CSNI-PWG/3 that inconsistencies were being revealed in predictive capabilities of a variety of fracture assessment methods, especially in ductile fracture applications. As a consequence, the CSNI/FAG was formed to evaluate fracture prediction capabilities currently used in safety assessments of nuclear components. Members are from laboratories and rescarch organizations in Western Europe, Japan, and the United States of America (USA). On behalf of the CSNI/ FAG, the U.S. Nuclear Regulatory Commission's (NRC's) Heavy-Section Steel Technology (HSST) Program at the Oak Ridge National Laboratory (ORNL) and the Gesellschaft fur Anlagen-und Reaktorsicherheit (GRS), Koln. Federal Republic of Germany (FRG) had responsibility for organization arrangements related to Project 
FALSIRE. The group is chaired by $\mathrm{H}$. Schulz from GRS, Koln, FRG.

Dodds, R. H., University of Illinois, et al., "Continuum and Micromechanics Treatment of Constraint in Fracture," NUREG/CR-5971, U.S. Nuclear Regulatory Commission, Washington, D.C., July 1993.

Two complementary methodologies are described to quantify the effects of crack-tip stress triaxiality (constraint) on the macroscopic measures of elastic-plastic fracture toughness, $J$ and CTOD. In the continuum mechanics methodology, two parameters, $\mathbf{J}$ and $Q$, suffice to characterize the full range of near-tip environments at the onset of fracture. A micromechanics methodology is described which predicts the toughness locus using crack-tip stress fields and critical J-values from a few fracture toughness tests. A robust micromechanics model for cleavage fracture has evolved from the observations of a strong, spatial selfsimilarity of crack-tip principal stresses under increased loading and across different fracture specimens. This report explores the fundamental concepts of the J-Q description of crack-tip fields, the fracture toughness locus and micromechanics approaches to predict the variability of macroscopic fracture toughness with constraint under elastic-plastic conditions. Computational results are presented for a surface cracked plate containing a 6:1 semi-elliptical, $a=t / 4$ flaw subject remote uniaxial and biaxial tension.

Hiser, A. L. and Mayfield, M. E., U.S. Nuclear Regulatory Commission, "Proceedings of the Seminar on Assessment of Fracture Prediction Technology: Piping and Pressure Vessels," NUREG/CP-0037, U.S. Nuclear Regulatory Commission, Washington, D.C., February 1991.

The 1990 Pressure Vessel and Piping Conference, sponsored by the American Society of Mechanical Engineers (ASME), was held in Nashville, Tennessee from June 18 to June 21, 1990. As part of that conference, representatives from the USNRC and AEA Technology in the United Kingdom jointly organized two panel sessions to discuss the current state of fracture prediction technologies for piping and pressure vessels. A total of nine presentations were given, contrasting analytical predictions with experimental result. This docurnent provides summaries of each presentation and copies of the pertinent figures and other visual aids. This information has been compiled and published to permit reasonably prompt disseminations of the information presented. Based on the information presented during these two panel sessions, it appears that, while the current state of fracture prediction technology is reasonably well advanced, more work is needed to provide analysis methods capable of accurately predicting ductile crack extension.

Keeney-Walker, J., et al., Oak Ridge National Laboratory, "An Investigation of Crack-Tip Stress Field Criteria for Predicting Cleavage-Crack Initiation," NUREG/CR-5651, U.S. Nuclear Regulatory Commission, Washington, D.C., September 1991.

Cleavage crack initiation in large-scale wide-plate (WP) specimens could not be accurately predicted from small, compact (CT) specimens utilizing a linear elastic fracture mechanics, $\mathrm{K}_{\mathrm{Ic}}$, methodology. In the wide-plate tests conducted by the HeavySection Steel Technology Program at Oak Ridge National Laboratory, crack initiation has consistently occurred at stress intensity $\mathrm{K}_{\mathrm{I}}$ values ranging from two to four times those predicted by the CT specimens. The work centers around nonlinear twoand three- dimensioral funite-element analyses of the crack-tip stress fielcs in these geometries. Analyses were conducted on ( $\mathrm{T}$ and WP specimens for which cleavage initiation fracture had been measured in laboratory tests. The local crack-tip fields generated for these specimens were then used in the evaluation of fracture correlation parameters to augment the $\mathrm{K}_{\mathrm{I}}$ parameter for predicting cleavage initiation. Parameters of hydrostatic constraint and of maximum principal stress, measured volumetrically, are included in these evaluations. The results suggest that the cleavage initiation process can be correlated with the local crack-tip fields via a maximum principal stress critcrion based on achieving a critical area within a critical stress contour. This criterion has been successfully applied to correlate cleavage initiation in $\mathrm{ZT}-\mathrm{CT}$ and WP specimen geometries.

Keeney-Walker, J. and Bass, B. R., Oak Ridge National Laboratory, "A Comparison of Analysis Methodologies for Predicting Cleavage Arrest of a Deep Crack in a Reactor Pressure Vessel Subjected to Pressurized-Thermal-Shock Loading Conditions," NUREG/CR-5793, U.S. Nuclear Regulatory Commission, Washington, D.C., September 1992.

Several calculational procedures are compared for predicting cleavage arrest of a deep crack in the wall of a prototypical reactor pressure vessel (RPV) subjected to pressurized-thermal-shock (PTS) types of loading conditions. Three procedures examined in this study used the following models: (1) a static finite-element model (full bending); (2) a radially constrained static model; and (3) a thermoelastic dynamic finite-clement 
model. A PTS transient loading condition was selected that produced a decp arrest of an axially oriented, initially shallow crack according to calculational results obtained from the static (fullbending) model. Results from the two static models were compared with those generated from the detailed thermoelastic dynamic finite element analysis. The dynamic analyses modeled cleavage-crack propagation using a nod-release technique and application- and gencration-mode methodologies. Comparisons presented here indicate that the degree to which dynamic solutions can be approximated by static models is highly dependent on several factors, including the material dynamic fracture curves and the propensity for cleavage rcinitiation of the arrested crack under PTS loading conditions. Additional work is required to develop and validate a satisfactory dynamic fracture toughness model applicable to postcleavage arrest conditions in an RPV.

Keency-Walker, J. and Bass, B. R., Oak Ridge National Laboratory, "ORNOZL: A Finite-Element Mesh Generator for Nozzle-Cylinder Intersections Containing Inner-Corner Cracks," NUREG/ CR-5872, U.S. Nuclear Regulatory Commission, Washington, D.C., September 1992.

This report describes the ORNOZL finiteelement mesh generator program for computational fracture mechanics analysis. The program automatically generates a three-dimensional (3-D) finite-element model for four different geometries of a corner crack in a nozzle-cylinder intersection. ORNOZL generates a core of special wedge or collapsed prism elements at the crack front to introduce the appropriate stress singularity at the crack tip. Regular 20-noded isoparametric brick elements are used away from the crack front in the modeling. Also, an option is included that allows for an embedded or penetrating crack in clad materials. As few as five input cards are required to execute the program. ORNOZL is part of a three-program system, ORNOZL-ADINA-ORVIRT, which addresses linear or nonlinear fracture in 2- or 3-D crack geometries. ORNOZL creates files containing nodal point coordinates and element connectivities that have formats compatible with the ADINA structural analysis program. ORVIRT is a post-processor to ADINA and employs a virtual crack extension technique to compute energy release rates at specified positions along the crack front.

Keeney-Walker, J., et al., Oak Ridge National Laboratory, "Finite-Length Surface Crack Propagation in Clad Cylinders," NUREG/CR-5915, U.S. Nuclear
Regulatory Commission, Washington, D.C., November 1992.

Licensing issues within the nuclear industry dictate a need to investigate the effects of cladding on the extension of small finite-length cracks near the inside surface of a vessel. Limited experimental data and analyses indicate that cladding can inhibit the propagation of certain shallow flaws. This report describes an analytical study which was carried out to determine (1) the minimum flaw depth for crack initiation under P'IS loading for semicircular surface flaws in a clad reacter pressure vessel and (2) the impact, in terms of the conditional probability of vessel failure, of using a semicircular surface flaw as the initial flaw. The analytical results indicate that, for initiation, a much deeper critical crack depth is required for the finite-length flaw than for the infinite-length flaw. Probabilistic analysis of selected PIS transients produced a substantial decrease in the conditional probability of failure for a finite-length flaw mode'. It is recommended that a testing program be carricd out utilizing clad cruciform and clad cylindrical test specimens. The completed experimental and analytical research will provide a basis for introducing a refined treatment of surface flaw initial geometry into PTS fracture analysis procedures. This report is designated HSST Report 129.

Kirk, M. T. and Dodds, R. H., University of Illinois, "J and CTOD Estimation Equations for Shallow Cracks in Single Edge Notch Bend Specimens," NUREG/ C.R-5969, U.S. Nuclear Regulatory Commission, Washington, D.C., July 1993.

Fracture toughness values determined using shallow cracked single edge notch bend, SE(B), specimens of structural thickness are useful for structural integrity assessments. Results from two dimensional plane strain finite-element analyses are used to develop J and CTOD estimation strategies appropriate for application to both shallow and deep crack SE(B) specimens. Crack depth to specimen width $(\mathrm{a} / \mathrm{W})$ ratios between 0.05 and 0.70 are modelled using Ramberg-Osgood strain hardening exponents $(\mathrm{n})$ between 4 and 50 . The estimation formulas divide $\mathbf{J}$ and CTOD into small scale yielding (SSY) and large scale yielding (LSY) components. For each case, the SSY component is determined by the linear elastic stress intensity factor, $\mathrm{K}_{\mathrm{I}}$. The formulas differ in evaluation of the LSY component. The techniques considered include: estimating $\mathrm{J}$ or CTOD irom plastic work based on load line displacement $\left(\mathrm{A}_{\mathrm{pl}} /\right.$ LLD), from plastic work based on crack mouth opening displacement $\left(\mathrm{A}_{\mathrm{pl}} / \mathrm{CMOD}\right)$, and from the plastic component of crack mouth opening 
displacement $\left(\mathrm{CMOD}_{\mathrm{pl}}\right) . \mathrm{A}_{\mathrm{p}} / \mathrm{CMOD}$ provides the most accurate $\mathrm{J}$ estimation possible.

Kirk, M. T. and Dodds, R. H., University of Illinois, "Approximate Techniques for Predicting Size Effects on Cleavage Fracture Toughness $\left(J_{c}\right)$." NUREG/ CR-5970, U.S. Nuclear Regulator, Commission, Washington, D.C., Juily 1 Ş่.

This investigation examines the ability of an elastic T-stress modified boundary layer (MBL) solution to predict stresses ahead of a crack tip in a variety of planar geometries. The approximate stresses are used as input to estimate the effective driving force for cleavage fracture $J_{0}$ using the micromechanically based approach introduced by Dodds and Anderson. Finite element analyses for a wide variety of planar cracked geometries are conducted which have elastic biaxiality parametc is ranging from -0.99 (very low constraint) to +2.96 (very high constraint). The magnitude and sign of $\beta$ indicate the rate at which crack-tip constraint changes with increasing applied load. All results pertain to a moderately strain hardening material (strain hardening exponent $\mathrm{n}$ of 10 ). These analyses suggest that $\beta$ is an effective indicator of both the accuracy of T-MBL estimates of $\mathrm{J}_{\mathrm{o}}$ and of applicability limits on evolving fracture analysis methodologies (i.e. T-MBL, J-Q, and $\mathrm{J} /$ $\mathrm{J}_{\mathrm{o}}$ ). Specifically, when $|\beta|>0.4$ these analyses show that the T-MBL approximation of $\mathrm{J}_{\mathrm{o}}$ is accurate to within $20 \%$ of a detailed finite-element analysis. As "structural type" configurations, i.e. shallow cracks in tension, generally have $|\beta|$ $>0.4$, it appears that only an elastic analysis may be needed to determine reasonably accurate $\mathrm{J}_{\mathrm{o}}$ values for structural conditions.

O'Dowd, N. P., Imperial College, and C. F. Shih, Brown University, "Two Parameter Fracture Mechanics: Theory and Applications," NUREG/CR-5958, U.S. Nuclear Regulatory Commission, Washington, D.C., February 1993.

A family of self-similar fields provides the two parameters required to characterize the full range of high- and low-triaxiality crack tip states. The two parameters, J and Q, have distinct roles: $J$ sets the size scale of the process zone over which large stresses and strains develop, while Q scales the near-tip stress distribution relative to a high triaxiality reference stress state. An immediate consequence of the theory is this: it is the toughness values over a range of crack tip constraint that fully characterize the material's fracture resistance. It is shown that $Q$ provides a common scale for interpreting cleavage fracture and duc- tile tearing data thus allowing both failure modes to be incorporated in a single toughness locus. The evolution of $Q$, as plasticity progresses from small scale yielding to fully yielded conditions, has been quantified for several crack geometries and for a wide range of material strain hardening properties. An indicator of the robustness of the $\mathrm{J}-\mathrm{Q}$ fields is introduced; $\mathrm{Q}$ as a field parameter and as a pointwise measure of stress level is discussed.

Rosenfield, A. R. and Marschall, C. W., Battelle Memorial Institute, "Fracture Mechanics Based Failure Analysis," NUREG/CR-5860, U.S. Nuclear Regulatory Commission, Washington, D.C., June 1992.

Twenty case studies involving the application of fracture mechanics to structural integrity have been reviewed and compared with a similar report published in 1978. Sixteeli of the new cases discuss failures, while four are fitness-for-purpose analyses (i.e., evaluation of safe operating conditions of defect-containing structures). Compared with the earlier study, no significant improvement in accuracy of failure analysis was detected. However, expert opinion suggests that there has been significant improvement in fitness-for-purpose analysis.

Shum, D. K., et al., Oak Ridge National Laboratory, "Analytical Studies of Transverse Strain Effects on Fracture Toughness for Circumferentially Oriented Cracks," NUREG/CR-5592, U.S. Nuclear Regulatory Commission, Washington, D.C., April 1991.

The objective of this report is to describe the development of analysis methods for estimating the decrease in crack-initiation toughness, from a reference plane strain value, due to positive straining along the crack front of a circumferential flaw in a reactor pressure vessel. The analysis methods are based on two different approaches that are currently being developed to analyze and explain the effects of transverse strain and stress states on fracture toughness. The first approach relates crack initiation with material failure at points within a few crack-tip opening displacements directly ahead of the crack tip. In this report the first approach is used to examine ductile crack initiation. This micromechanical approach thus provides a relation between fracture toughness and values of the effective stress and strain at failure that can be determined experimentally. The second approach focuses on the development of correlation parameters that relate fracture toughness with nominal stress and strain states. Candidate correlation parameters include, but are not limited to, the area enclosed within a selected maximum principal stress contour and 
the plastic zone size. In the first phase of this work, the scope of the present investigation is limited to crack-front constraint conditions that can be described in terms of conventional one-parameter (K or J), in-plane, near-tip field's and the transverse strain. To date, correlation parameter investigations have con entrated on the stress contour method, which is used to examine cleavage crack initiation. Validation checks of the analysis methods under study are being made by applying them to small- and large-scale fracture data. Preliminary estimates on the change in crack-initiation toughness associated with either negative or positive straining along a crack front have been obtained for conditions of contained crack-tip yielding. Results from the validation checks are promising but incomplete. The primary problem encountered in the validation checks is the absence of accurate descriptions of the near-tip stress and strain fields associated with the generation of some of these fracture data. In addition, there are reasons to believe that two-parameter in-plane approaches may be needed to characterize crack initiation in some of these tests. Included are recommendations for subsequent phases of the work considered necessary to provide more precise estimates on the effects of positive out-of-plane straining on the crackinitiation toughness for circumferentially oriented flaws.

Shum, D. K., et al., Oak Ridge National Laboratory, "Potential Change in Flaw Geometry of an Initially Shallow Finite-Length Surface Flaw During a Pressurized-Thermal-Shock Transient," NUREG/ CR-5968, U.S. Nuclear Regulatory Commission, Washington, D.C., September 1993.

This study presents preliminary estimates on whether an initially shallow, axially oriented, inner-surface finite-length flaw in PWR-RPV would tend to elongate in the axial direction and/ or deepen into the wall of the vessel during a postulated PTS transient. Analysis results obtained based on the assumptions of (1) linearelastic material response, and (2) cladding with same toughness as the base metal, indicate that a nearly semicircular flaw would likely propagate in the axial direction followed by propagation into the wall of the vessel. Note that these results correspond to initiation within the lower-shelf fracture toughness temperature range, and that their general validity within the lower-transition temperature range remains to be determined. The sensitivity of the numerical results and conclusions to the following analysis assumptions are evaluated: (1) reference flaw geometry along the entire crack front and especially within the clad- ding region; (2) linear-elastic vs clastic-plastic description of material response; and (3) base-material-only vs bimaterial cladding-base vessel-model assumption. The sensitivity evaluation indicates that the analysis results are very sensitive to the above assumptions. This report is designated HSST Report No. 139.

\section{Fracture Mechanics: Experimental - Component Testing}

Irwin, G. R., University of Maryland, "Use of Thickness Reduction to Estimate Values of K," NUREG/ CR-5697, U.S. Nuclear Regulatory Commission, Washington, D.C., November 1991.

\begin{abstract}
Using results for two 152-mm-thick wide-plate tests at the National Institute of Standards and Technology, estimates of $\mathrm{K}$ were made using the residual thickness reduction near the plane of fracture. These results corresponded well to the average of $\mathrm{K}$ values for leavage arrest and reinitiation obtained at Oak Ridge National Laboratory using generation-mode, dynamic-analysis computations.
\end{abstract}

Iskander, S. K., et al., Oak Ridge National Laboratory, "Experimental Results of Tests to Investigate Flaw Behavior of Mechanically Loaded Stainless Steel Clad Plates," NUREG/CR-5785, U.S. Nuclear Regulatory Commission, Washington, D.C., April 1992.

A small crack near the inner surface of clad nuclear reactor pressure vessels is an important consideration in the safety assessment of the structural integrity of the vessel. Four-point bend tests on large plate specimens, six clad and two unclad, were performed to determine the effect of stainless steel cladding upon the propagation of small surface racks subjected to stress states similar to those produced by pressurized thermal shock conditions. Results of tests at temperatures 10 and $60^{\circ} \mathrm{C}$ below the nil-ductility transition temperature have shown that a tough surface layer composed of cladding and heat-affected zone has arrested running flaws in clar plates under conditions where unclad plates have ruptured. Furthermore, the load-bearing capacity of clad plates with large subclad flaws significantly exceeded that of an unclad plate with a much smaller flaw. More testing is necessary to unambiguously single out whether it is the cladding or the heat-affected zone that is primarily responsible for the observed enhanced load-bearing capacity of plates. The compressive stresses that limited the depth to which the flaw could propagate are absent in a repressurization event. Nonetheless, the experiments show that if the surface layer is sufficiently tough, it could prevent a flaw, near the surface, 
from propagating along the surface. The flaw could tunnel below the surface, but a sufficiently tough surface layer would reduce the maximum stress intensity factor.

Naus, D. J., et al., Oak Ridge National Laboratory, "Crack-Arrest Behavior in SEN Wide Plates of LowUpper-Shelf Base Metal Tested Under Nonisothermal Conditions: WP-2 Series," NUREG/CR-5451, U.S. Nuclear Regulatory Commission, Washington, D.C., August 1990.

Six wide-plate crack-arrest tests (WP-2 Series) are discussed in this report. Each test utilized either a 1 x 1 x $0.1-\mathrm{m}$ or a $1 \times 1 \times 0.15-\mathrm{m}$ thick single-edge notch specimen $(\mathrm{a} / \mathrm{W}=0.2)$, fabricated from a low-upper-shelf base material, that was subjected to a linear thermal gradient along the plane of crack propagation. The tests were conducted at the National Institute of Standards and Technology and were designed to provide fracture-toughness measurements at temperatus es approaching or above the onset of the Charpy upper-shelf regime, in a rising toughness region, and with an increasing driving force. Results obtained from these tests have produced crack-arrest toughness values well above the limit recognized by the current ASME guidelines (220 $\mathrm{MPa} \sqrt{\mathrm{m}}$ ) with arrests occurring at up to $102^{\circ} \mathrm{C}$ above the material DW-NDT $\left(60^{\circ} \mathrm{C}\right)$. The fracture data support: (1) use of fracture mechanics concepts to analyze cleavage run-arrest events, (2) treatment of cleavage and ductile fracture modes as separate events, and (3) fact that cleavage arrest occurs above the ASME limit.

Pennell, W. E., Oak Ridge National Laboratory, "Heavy Section Steel Technology Program. Scmiannual Progress Report for April - September 1989," NUREG/CR-4219, Vol. 6, No. 2, U.S. Nuclear Regulatory Commission, Washington, D.C., September 1990.

The Heavy-Section Steel Technology (HSST) Program studies concern all areas of the technology of materials fabricated into thick-section, primary-coolant containment systems of lightwater-cooled nuclear power reactors. The focus is on the behavior and Structural integrity of stecl reactor pressure vessels (RPVs) containing cracklike flaws. During this period, analytical efforts included examining the influence of high crackarrest toughness on RPV integrity and an increased emphasis on evaluating large international structural experiments. Two areas of NRC topical support were continued: (1) the evaluation of mechanisms for enhanced low-temperature, low-flux irradiation embrittlement that may af- fect the integrity of RPV supports; and (2) an overall assessment of low upper-shelf (LUS) welds in RPVs with special emphasis on reevaluating ductile tearing criteria. The first four stubpanel crack-arrest tests were performed. Post test material characterization was performed for cladplate and wide-plate Series 2 test materials. Statistical analyses were performed on the data from the Fifth HSST Irradiation Series on the study of $\mathrm{K}_{\mathrm{Ic}}$ shifts. Analysis of the irradiated fracturetoughness testing was completed for the Seventh HSST Irradiation Series on cladding. Detailed planning was begun for the next pressurizedthermal-shock experiment, PTSE-4, to examine the extent of ductile tearing and its interaction with cleavage fracture in an LUIS weld metal.

Pennell, W. E., Oak Ridge National Laboratory, "Heavy Section Stecl Technology Prograin. Semiannual Progress Report for October 1989 - March 1990," NUREG/CR-4219, Vol. 7, No. 1, U.S. Nuclear Regulatory Commission, Washington, D.C., March 1991.

The Heavy Section Steel Technology (HSST) Program is conducted for the Nuclear Regulatory Commission (NRC) by Oak Ridge National Laboratory (ORNL). The program focus is on the development and validation of technology for the assessment of fracture prevention margins in commercial nuclear reactor pressure vessels. In the current reporting period, reorganization of the original HSST program into separate programs with emphasis on fracture mechanics technology (HSST) and materials irradiation effects (HSSI) has been completed. The revised HSST program is organized in 10 Tasks. These are (1) Program Management, (2) Fracture Methodology and Analysis, (3) Material Characterization Tasks, (4) Special Technical Assistance, (5) Crack Arrest Technology, (6) Clcavage Crack Initiation, (7) Cladding Evaluations, (8) PressurizedThermal-Shock Technology, (9) Analysis Methods Validation, (10) Fracture Evaluation Tests. The program tasks have been structured to place emphasis on the resolution fracture issues with near-term licensing significance.

Pennell, W. E., Oak Ridge National Laboratory, "Heavy Section Steel Technology Program. Semiannual Progress Report for April - September 1990," NUREG/CR-4219, Vol. 7, No. 2, U.S. Nuclear Regulatory Commission, Washington, D.C., September 1991.

The Heavy-Section Steel Technology (HSST) Program is conducted for the Nuclear Regulatory Commission (NRC) by Oak Ridge National Laboratory (ORNL). The program focus is on the 
development and validation of technology for the assessment of fracture-prevention margins in commercial nuclear reactor pressure vessels. Reorganization of the original HSST Program into separate programs with emphasis on fracturemechanics technology (HSST) and materials-irradiation effects (HSSI) was previously completed. The revised HSST Program is organized in 10 tasks: (1) program management, (2) fracture methodology and analysis, (3) material characterization and properties, (4) special technical assistance, (5) crack-arrest technology, (6) cleavagecrack initiation, (7) cladding evaluations, (8) pressurized-thermal-shock technology, (9) analysis methods validation, and (10) fracture evaluation tests. The program tasks have been structured to place emphasis on the resolution fracture issues with near-term licensing significance. Resources to exec'ite the research tasks are drawn from ORNL with subcontract support from universities and other research laboratories. Close contact is maintained with related research programs both in the United States and abroad.

Pennelı, W. E., Oak Ridge National Laboratory, "Heavy Section Steel Technology Program. Semiannual Progress Report for October 1990 - March 1991," NUREG/CR-4219, Vol. 8, No. 1, U.S. Nuclear Regulatory Commission, Washington, D.C., February 1992.

The Heavy-Section Steel Technology (HSST) Program is conducted for the Nuclear Regulatory Commission (NRC) by Oak Ridge National Laboratory (ORNL). The program focus is on the development and validation of technology for the assessment of fracture-prevention margins in commercial nuclear reactor pressure vessels. Reorganization of the original HSST Program into separate programs with emphasis on fracturemechanics technology (HSST) and materialsirradiation effects (HSSI) was previously completed. The revised HSST Program is organized in 10 tasks: (1) program management, (2) fracture methcdology and analysis, (3) material characterization and properties, (4) special technical assistance, (5) crack-arrest technology, (6) cleavagecrack initiation, (7) cladding evaluations, (8) pressurized-thermal-shock technology, (9) analysis methods validation, and (10) fracture evaluation tests. The program tasks have been structured to place emphasis on the resolution fracture issues with near-term licensing significance. Resources to execute the research tasks are drawn from ORNL with subcontract support from universities and other research laboratories. Close contact is maintained with related research programs both in the United States and abroad.
Pennell, W. E., Oak Ridge National Laboratory, "Heavy Section Stecl Technology Program. Semiannual Progress Report for April - September 1991," NUREG/CR-4219, Vol. 8, No. 2, U.S. Nuclear Regulatory Commission, Washington, D.C., April 1992.

The Heavy-Section Steel Technology (HSSI) Program is conducted for the Nuclear Regulatory Commission by Oak Ridge National Laboratory (ORNL). The program focus is on the development and validation of technology for the assessment of fracture-prevention margins in commercial nuclear reactor pressure vessels. The HSST Program is organized in 10 tasks: (1) program management, (2) fracture methodology and analysis, (3) material characterization and propertics, (4) special technical assistance, (5) fracture analysis computer programs, (6) cleavage-crack initiation, (7) cladding evaluations, (8) pressurized-thermal-shock technology, (9) analysis methods validation, and (10) fracture evaluation tests. The program tasks have been structured to place emphasis on the resolution of fracture issues with near-tern licensing significance. Resources to execute the research tasks are drawn from ORNL with subcontract support from universities and other research laboratories. Close contact is maintained with related research programs both in the United States and abroad.

Pennell, W. E., Oak Ridge National Laboratory, "Heavy Section Steel Technology Program. Semiannual Progress Report for October 1991 - March 1992,"NUREG/CR-4219, Vol. 9, No. 1, U.S. Nuclear Regulatory Commission, Washington, D.C., November 1992.

The Heavy-Section Steel Technology (HSST) Program is conducted for the Nuclear Regulatory Commission (NRC) by Oak Ridge National Laboratory (ORNL). The program focus is on the development and validation of technology for the assessment of fracture-prevention margins in commercial nuclear reactor pressure vessels. The HSST Program is organized in 11 tasks: (1) program management; (2) fracture methodology and analysis; (3) material characterization and properties; (4) special technical assistance; (5) fracture analysis computer programs; (6) cleavage-crack initiation; (7) cladding evaluations; (8) pressurized-thermal-shock technology; (9) analysis methods validations; (10) fracture evaluation tests; and (11) warm prestressing. The program tasks have been structured to place emphasis on the resolution fracture issues with near-term licensing significance. Resources to execute the research tasks are drawn from ORNL with subcontract support from universities and other research laboratories. Close contact is maintained 
with the sister Heav'-Section Steel Irradiation (HSSI) Program at ORNL and with related research programs both in the United States and abroad. This report provides an overview of principal developments in each of the 11 program tasks from October 1, 1991 to March 31, 1992.

\section{Fracture Mechanics: Experimental - Standard Specimen Testing}

Dally, J. W., University of Maryland, et al., "Lower Bound Initiation Toughness with a Modified Charpy Specimen," NUREG/CR-5703, U.S. Nuclear Regulatory Commission, Washington, D.C., November 1991.

"Lower-bound" initiation toughness of A 533 B reactor grade steel was determined over the temperature range from 0 to $57^{\circ} \mathrm{C}$ by using a modified-Charpy specimen. The lower-bound measurements were attained by utilizing the following procedures: (1) dynamic loading, (2) modification of the geometry of the specimen, and (3) axial precompression of the notch. The report describes in detail the key features of the modified geometry, the method of precompressing the specimens, and the strain-gage procedure. The dynamic initiation toughness $\mathrm{K}_{\mathrm{Id}}$, which correlates with the lower-bound toughness, was determined by analyzing strain-time records from the specimen. The results from a fractogaphic analysis were correlated with those from the straintime analysis. An empirical correlation was developed relating $K_{I}$ to the energy absorbed $E_{c v}$ during the fracture of the specimen. Finally, the lower-bound toughness from this study compared favorably with $\mathrm{K}_{\mathrm{I}}$ and $\mathrm{K}_{\mathrm{Id}}$ measurements from the same material established in other programs.

Joyce, J. A., U.S. Naval Academy, and Hackett, E. M., David Taylor Research Center, "Extension and Extrapolation of J-R Curves and Their Application to the Low Upper Shelf Toughness Issue," NUREG/ CR-5577, U.S. Nuclear Regulatory Commission, Washington, D.C., March 1991.

This document develops methods of measuring experimentally the limits of valid fracture mechanics data that can be obtained from small fracture mechanics specimens. The proposed technique generally shows that present ASTM limits are overly conservative and the new technique would allow almost a three-fold increase in the amount of crack extension allowed in the testing of a surveillance specimen. Analytic relationships are then developed to allow use of the new experimentally measured limit to J controlled crack growth for design or failure analysis applica- tions to correlate best with the omega criterion which defines limits on both the maximum J level and the maximum crack extension allowable for a particular specimen size and material toughness combination. The final section looks at the problem of extrapolation of J-R curve data when needed for a structure fracture analysis. Several forms of extrapolation relationships are compared from the point of view of accurate and conservative extrapolation, particularly from the standpoint of tearing instability analysis of a growing, ductile crack on the material upper shelf.

Joyce, J. A., U.S. Naval Academy, et al., "Comparison of $\mathrm{J}_{\mathrm{Ic}}$ and J-R Curves for Short Crack and Tensilely Loaded Specimen Geometries of a High Strength Structural Steel," NUREG/CR-5879, U.S. Nuclear Regulatory Commission, Washington, D.C., November 1992.

This paper describes an experimental program which had the objective of developing a series of J-R curve data from laboratory specimens of varied constraint. Constraint was varied by testing specimens with different thicknesses, crack lengths, and mode of loading. All specimens were relatively small and were kept simple in geometry and loading to allow estimation of the applied $\mathrm{J}$ integral. All tests were conducted on high strength structural steel, at ambient temperature, on the ductile upper shelf for this alloy. Results of these tests have shown that different constraint condition can dramatically affect the $\mathrm{J}_{\mathrm{Ic}}$, and the $\mathrm{J}-\mathrm{R}$ curve for the full range of crack lengths and loading modes studied here. The results are compared in terms of the "T Stress" $T_{\sigma}$ parameter and the $Q$ constraint parameter, but the trends in the data do not seem to correlate well with either parameter. Although both the $\mathrm{T}_{\sigma}$ and $\mathrm{Q}$ parameters predict that the single edge notched tensile bar SE(T) would have relatively high constraint. this geometry demonstrated the highest $\mathrm{J}_{\mathrm{Ic}}$ properties. The double edge notched bars were predicted by the $T_{\sigma}$ or $Q$ parameters to be a low constraint geometry, however this geometry resulted in $\mathrm{J}_{\mathrm{Ic}}$ results lower than those measured on standard deeply crack bend bars.

Joyce, J. A., U.S. Naval Academy, and Link, R. E., Naval Surface Warfare Center, "The Effect of Electric Discharge Machined Notches on the Fracture Toughness of Several Structural Alloys," NUREG/ CR-5981, U.S. Nuclear Regulatory Commission, Washington, D.C., September 1993.

Recent computational studies of the stress and strain fields at the tip of very sharp notches have shown that the stress and strain fields are very weakly dependent on the initial geometry of the 
notch once the notch has been blunted to a radius that is 6 to 10 times the initial root radius. It follows that if the fracture toughness of a material is sufficiently high so that fracture initiation does not occur in a specimen until the crack-tip opening displacement (CTOD) reaches a value from 6 to 10 times the size of the initial notch tip diameter, then the fracture toughness will be independent of whether a fatigue crack or a machined notch served as the initial crack. In this experimental program the fracture toughness $\left(\mathrm{J}_{\mathrm{Ic}}\right.$ and $\mathrm{J}$ resistance (J-R) curve, and CTOD) for several structural alloys was measured using specimens with conventional fatigue cracks and with EDM machined notches. The results of this program have shown, in fact, that most structural materials do not achieve initiation CTOD values on the order of 6 to 10 times the radius of even the smallest EDM notch tip presently achievable. It is found furthermore that tougher materials do not seem to be less dependent on the type of notch tip present. Some materials are shown to be much more dependent on the type of initial notch tip used, but no simple pattern is found that relates this observed dependence to the material strength, toughness, or strain hardening rate.

Landes, J. D., University of Tennessee, "Extrapolation of the J-R Curve for Predicting Reactor Vessel Integrity," NUREG/CR-5650, U.S. Nuclear Regulatory Commission, Washington, D.C., January 1992.

The work in this report was conducted in support of the issues studied by the U.S. Nuclear Regulatory Commission $\mathrm{J}_{\mathrm{D}} / \mathrm{J}_{\mathrm{M}}$ Working Group during the period 1987-1989. The major issues studied were the J-R curve extrapolation techniques for using small-specimen test results to predict ductile instability in larger structures where the extent of crack extension from the small-specimen test was not sufficient. An additional issue was raised during the course of this work by the testing of a low-upper-shelf A 302 steel. The results from these tests were not typical of ductile fracture in many steels and suggested that small-specimen J-R curves may not predict the behavior of large structures in some cases. The cause of this behavior was studied as well as the consequences of using the J-R curve results from small specimens of this kind of material. Finally, a discussion and recommendations are given relating to the use of extrapolated J-R curves.
McCabe, D. E., Oak Ridge National Laboratory, "A Comparison of Weibull and $\beta_{\mathrm{Ic}}$ Analysis of Transition Range Fracture Toughness Data," NUREG/ CR-5788, U.S. Nuclear Regulatory Commission, Washington, D.C., January 1992.

Characteristics of extremal statistics that are used to predict size effects on cleavage fracture toughness in the transition range were explored. A 533 grade B steel base and weld metals were tested using compact specimens ranging in size from $1 / 2 \mathrm{TC}(\mathrm{T})$ to $8 \mathrm{TC}(\mathrm{T})$ and with sufficient replication in some cases to provide good fits to Weibull distributions. The classical specimen size effect on data scatter and median $\mathrm{K}_{\mathrm{Jc}}$ toughness at a given test temperature was observed in the low-to mid-transition range. These effects were well predicted with extremal statistics. However, the same moc' $\rightarrow$ is not applicable on the lower shelf and it also becomes extremely weak and unreliable in the mid- to high-transition range. The Irwin $\beta_{c}-\beta_{\text {Ic }}$ relationship was also explored as a model and was found to predict similar size effects. The predictive characteristics of the latter seemed better suited to deal with the diminution of size effects in the near- to low-shelf toughness range. In the rising toughness part of the transition, the predictive characteristics were about the same as the statistical model up to where $\beta_{\mathrm{c}}\left(\beta_{\mathrm{Jc}}\right.$ in this study) of the baseline (small specimen) data were $\pi$ or less. This work could be used in the establishment of a framework for transition temperature test criteria. Upper- and lower- bound ( $\beta_{\mathrm{Jc}}$ criteria could be used to define optimum conditions for the application of either of the aforementioned models. For surveillance programs, sensible rules should be specified as to specimen size requirements and numbers of specimens to be tested in order to apply these analytical models. Another need would be the definition of a procedure for the Weibull distribution fitting. The present report suggests items to be considered for requirements in application of these predictive techniques.

McCabe, D. E., Oak Ridge National Laboratory, "Evaluation of Crack Pop-ins and the Determination of Their Relevance to Design Considerations," NUREG/CR-5952, U.S. Nuclear Regulatory Commission, Washington, D.C., February 1993.

The issue with regard to crack pop-ins is to determine if such events are significant to design considerations. The literature contains ample evidence of pop-in occurrences, but scant information is offered on how pop-ins should be han- 
dled as an issue for design problems. Because there are two types of cleavage crack origins, the problem was subdivided into two classes of materials, monolithic and weldments with brittle zones. The weidment situation can be analyzed as a crack-arrest toughness capability problem, following the recommendations of Sumpter et al. For monolithic materials, pop-ins are more dangerous, since they appcar to be a part of the more commonly encountered full-cleavage $\mathrm{K}_{\mathrm{Jc}}$ instability distributions. A recommendation is made on how to determine if pop-in events lie outside of the larger body of $\mathrm{K}_{\mathrm{Jc}}$ instabilities. The evaluation procedure recommended by the American Society for Testing and Materials for pop-ins seems to dismiss the possibility that small crack jumps can be a safety-related issue. The present work suggests that nearly all pop-in events, regardless of the magnitude of crack jump, are relevant to safety issues.

Rolfe, S. T., University of Kansas, "The i ehavior of Shallow Flaws in Reactor Pressure Vessels," NUREG/CR-5767, U.S. Nuclear Regulatory Commission, Washington, D.C., November 1991.

The objective of this report is to recommend those research investigations that are necessary to understand the phenomenon of shallow behavior as it affects fracture toughness so that the results can be used properly in the structural margin assessment of reactor pressure vessels (RPVs) with flaws. Preliminary test results of A 533 B steel show an elevated crack-tip opening displacement toughness similar to that observed for structural steels tested at the University of Kansas. Thus, the inherent resistance to fracture initiation of A 533 B steel with shallow flaws appears to be higher than that used in the current American Society of Mechanical Engineers design curves based on testing fracture-mechanics specimens with deep flaws. If this higher toughness of laboratory specimens with shallow flaws can be transferred to a higher resistance to failure in RPV design or analysis, then the actual margin of safety in nuclear vessels with shallow flaws would be greater than is currently assumed on the basis of deep-flaw test results. This report reviews those factors and makes recommendations of studies that are needed to assess the transferability of shallow-flaw toughness test results to the structural margin assessment of RPV with shallow flaws.

Theiss, T. J., Oak Ridge National Laboratory, et al., "Experimental and Analytical Investigation of the Shallow - Flaw Effect in Reactor Pressure Vessels,"
NUREG/CR-5886, U.S. Nuclear Regulatory Commission, Washington, D.C., July 1992.

The Heavy-Section Stecl Technology (HSST) Program is investigating the increase in effective fracture toughness of A $533 \mathrm{~B}$ steel associated with shallow flaws and the implications of the shallow-flaw effect on reactor pressure vessel (RPV) life assessments. Test data from beams indicate a significant increase in the fracture toughness of shallow-crack specimens compared with decp-crack specimens in the transition region of the toughness curve for unirradiated $\mathrm{A}$ $533 \mathrm{~B}$ steel. If the toughness increase present in the test specimens were also present in a reactor vessel, the impact on pressurized-thermal shock (PTS) analyses could be significant. To facilitate transferability of the specimen data to an RPV, post-test finite-element analyses have been performed on sèveral test specimens and a reactor vessel for a single (PTS) transient. The analyses are sufficiently refined to allow interpretation of the results in terms of the J-integral and the socalled Q-stress parameter under plane-strain analysis assumptions. A negative Q-stress parameter is indicative of a loss of crack-tip constraint, which is associated with an increase in the fracture toughness. Analyses of the test specimens indicate that at the onset of crack initiation the deep-crack specimens exhibit an essentially zero Q-stress parameter but that the shallow-crack specimen exhibits a Q-stress parameter of about -0.7 , which indicates a substantial loss of constraint in the shallow-crack beam. Using the test data and post-test analysis, a locus of toughness data in terms of the J-integral and the Q-stress parameter has been constructed for a particular temperature. Analyses were also performed on an RPV with a shallow flaw under PTS loading conditions up to the maximum value of J. At maximum J, the analyses reveal a Q-stress parameter about -0.2 to -0.4 , which indicates some constraint loss but less than in the shallow-rack test specimens. Considering the RPV in terms of J-integral and Q-stress suggests there may be a larger margin of safety than would be found using the J-integral alone. Thermal-shock data, which were generated using cylindrical vessels under thermal shock loading, show no significant increase in toughness even for shallow-flaw depths. The thermal shock data seem to indicate two offsetting effects: a shallow-flaw effect, which increases toughness, and an out-of-plane (biaxial) stress effect, which decreases toughness. Additional work is necessary to resolve outstanding issucs for applying shallow-crack data to an RPV and validating the J-Q technique for fracture evaluations. 
Theiss, T. J., et al., Oak Ridge National Laboratory, "Initial Results of the Influence of Biaxial Loading on Fracture Toughness," NUREG/CR-6036, U.S. Nuclear Regulatory Commission, Washington, D.C., June 1993.

A testing program to examine the influence of biaxial loads on the fracture toughness of shallowflaw specimens under conditions prototypic of a reactor pressure vessel was begun. Existing data suggest that shallow-flaw specimens under biaxial loading will exhibit a toughness reduction compared to comparable uniaxial specimens. Quantification of this toughness reduction is the main goal of the biaxial fracture toughness program. A cruciform specimen with a two-dimensional shallow through-thickness flaw under a biaxial load ratio of $0.6: 1$ was used for biaxial fracture toughness testing. The critical fracture load for each specimen was approximately the same, but the uniaxial specimen withstood substantially more deformation at failure than did the biaxial specimens. Three-dimensional, elastic-plastic, finite-element post-test analyses were necessary to estimate fracture toughness. In all cases, agreement between the measured and computed load vs deformation responses was excellent. Toughness values for the cruciform specimens were compared with data from previously tested, deepand shallow-crack specimens. Results from these tests indicate that the shallow-crack toughness increase is partially, but not totally, removed by the application of biaxial loading. However, additional data are required to solidify these conclusions. A proposed test matrix for additional uniaxial and biaxial testing is described. This report has been designated HSST Report No. 138.

\section{NDE - Continuous Monitoring (Acoustic Emission)}

Hutton, P. H., et al., Pacific Northwest Laboratory, "Acoustic Emission/Flaw Relationships for Inservice Monitoring of LWRS," NUREG/CR-5645, U.S. Nuclear Regulatory Commission, Washington, D.C., October 1991.

The program concerning Acoustic Emission/Flaw Relationships for Inservice Monitoring of LWRs was initiated in FY76 with the objective of validating the application of acoustic emission (AE) to monitor nuclear reactor pressure-containing components during operation to detect cracking. The program has been supported by the U.S. Nuclear Regulatory Commission, Office of Nuclear Regulatory Research with supplemental support from the Tennessee Valley Authority. Research and development has been performed by Pacific
Northwest Laburatory, operated for the Department of Ener $\cdots y$ by Battelle Memorial Institute. The program, ss shown the feasibility of continuous, on-line $\mathrm{AE}$ monitoring to detect crack growth and produced validated methods for applying the technology. Included are relationships for estimating flaw severity from $\mathrm{AE}$ data and field applications at Watts Bar Unit 1 Reactor, Limerick Unit 1 Reactor, and the High Flux Isotope Reactor. This report discusses the program scope and organization, the three program phases and the results obtained, standard and code activities, and instrumentation and software developed under this program.

\section{NDE - In-Service Inspection}

Doctor, S. R., et al., Pacific Northwest Laboratory, "Nondestructive Examination (NDE) Reliability for Inservice Inspection of Light Water Reactors. Semiannual Report for April - September 1989," NUREG/CR-4469, Vol. 11, U.S. Nuclear Regulatory Commission, Washington, D.C., August 1991.

Evaluation and Improvement of NDE Reliability for Inservice Inspection of Light Water Reactors (NDE Reliability) Program at the Pacific Northwest Laboratory was established by the Nuclear Regulatory Commission to determine the reliability of current inservice inspection (ISI) techniques and to develop recommendations that will ensure a suitably high inspection reliability. The objectives of this program include determining the reliability of ISI performed on the primary systems of commercial light-water reactors (LWRs); using probabilistic fraciure mechanics analysis to determine the impact of NDE unreliability' on system safety; and evaluating reliability improvements that can be achieved with improved and advanced technology. A final objective is to formulate recommended revisions to ASME Code and Regulatory requirements, based on material properties, service conditions, and NDE uncertainties. The program scope is limited to ISI of the primary systems including the piping, vessel, and other components inspected in accordance with Section XI of the ASME Code. This is a progress report covering the programmatic work from April 1989 through September 1989.

Doctor, S. R., et al., Pacific Northwest Laboratory, "Nondestructive Examination (NDE) Reliability for Inservice Inspection of Light Water Reactors. Semiannual Report for October 1989 - September 1990," NUREG/CR-4469, Vol. 12, U.S. Nuclear Regulatory Commission, Washington, D.C., May 1992.

The Evaluation and Improvement of NDE Reliability for Inservice Inspection of Light Water Reactors (NDE Reliability) Program at the Pacific 
Northwest Laboratory was established by the Nuclear Regulatory Commission to determine the reliability of current inservice inspection (ISI) techniques and to develop recommendations that will ensure a suitably high inspection reliability. The objectives of this program include: determining the reliability of ISI performed on the primary systems of commercial light-water reactors (LWRs); using probabilistic fracture mechanics analysis to determine the impact of NDE unreliability on system safety; and evaluating reliability improvements that can be achieved with improved and advanced technology. A final objective is to formulate recommended revisions to ASME Code and Regulatory requirements, based on material properties, service conditions, and NDE uncertainties. The program scope is limited to ISI of the primary systems including the piping, vessel, and other components inspected in accordance with Section XI of the ASME Code. This is a progress report covering the programmatic work from October 1989 through September 1990.

Doctor, S. R., et al., Pacific Northwest Laboratory, "Nondestructive Examination (NDE) Reliability for Inservice Inspection of Light Water Reactors. Semiannual Report for October 1990 - March 1991," NUREG/CR-4469, Vol. 13, U.S. Nuclear Regulatory Commission, Washington, D.C., July 1992.

The Evaluation and Improvement of NDE Reliability for Inservice Inspection of Light Water Reactors (NDE Reliability) Program at the Pacific Northwest Laboratory was established by the $\mathrm{Nu}$ clear Regulatory Commission to determine the reliability of current inservice inspection (ISI) techniques and to develop recommendations that will ensure a suitably high inspection reliability. The objectives of this program include determining the reliability of ISI performed on the primary systems of commercial light-water reactors (LWRs); using probabilistic fracture mechanics analysis to determine the impact of NDE unreliability on system safety; and evaluating reliability improvements that can be achieved with improved and advanced technology. A final objective is to formulate recommended revisions to ASME Code and Regulatory requirements, based on material properties, service conditions, and NDE uncertainties. The program scope is limited to ISI of the primary systems including the piping, vessel, and other components inspected in accordance with Section XI of the ASME Code. This is a progress report covering the programmatic work from October 1990 through March 1991.
Doctor, S. R., et al., Pacific Northwest Laboratory, "Nondestructive Examination (NDE) Reliability for Inservice Inspection of Light Water Reactors. Semiannual Report for April 1991 - September 1991," NUREG/CR-4469, Vol. 14, U.S. Nuclear Regulatory Commission, Washington, D.C., July 1992.

The Evaluation and Improvement of NDE Reliability for Inservice Inspection of Light Water Reactors (NDE Reliability) Program at the Pacific Northwest Laboratory was established by the Nuci aar Regulatory Commission to d stermine the reliability of current inservice inspection (ISI) techniques and to develop recommendations that will ensure a suitably high inspection reliability. The objectives of this program include determining the reliability of ISI performed on the primary systems of commercial light-water reactors (LWRs); using probabilistic fracture mechanics analysis to det rmine the impact of NDE unreliability on syste $e_{\text {ul }}$ safety; and evaluating reliability improvements that can be achieved with improved and advanced technology. A final objective is to formulate recommended revisions to ASME Code and Regulatory requirements, based on material properties, service conditions, and NDE uncertainties. The program scope is limited to ISI of the primary systems including the piping, vessel, and other components inspected in accordance with Section XI of the ASME Code. This is a progress report covering the programmatic work from April 1991 through September 1991.

Doctor, S. R., et al., Pacific Northwest Laboratory, "Nondestructive Examination (NDE) Reliability for Inservice Inspection of Light Water Reactors. Semiannual Report for October 1991 - March 1992," NUREG/CR-4469, Vol. 15, U.S. Nuclear Regulatory Commission, Washington, D.C., September 1993.

The Evaluation and Improver.ent of NDE Reliability for Inservice Inspection of Light Water Reactors (NDE Reliability) Pregram at the Pacific Northwest Laboratory was established by the Nuclear Regulatory Commission to determine the reliability of current inservice inspection (ISI) techniques and to develop recommendations that will ensure a suitably high inspection reliability. The objectives of this program include determining the reliability of ISI performed on the primary systems of commercial light-water reactors (LWRs); using probabilistic fracture mechanics analysis to determine the impact of NDE unreliability on system safety; and evaluating reliability improvements that can be achieved with improved and advanced technology. A final objective is to formulate recommended revisions to ASME Code and Regulatory requirements, based on material properties, service conditions, and 
NDE uncertainties. The program scope is limited to ISI of the primary systems including the piping, vessel, and other components inspected in accordance with Section XI of the ASME Code. This is a progress report covering the programmatic work from October 1991 through March 1992.

Heasler, P. G., et al., Pacific Northwest Laboratory, "Statistically Based Reevaluation of PISC-II Round Robin Test Data," NUREG/CR-5410, U.S. Nuclear Regulatory Commission, Washington, D.C., May 1993.

This report presents a re-analysis of an international PISC-II round-robin inspection results using formal statistical techniques to account for experimental error. The analysis examines: U.S. team performance vs. other participants performance; flaw sizing performance and errors associated with flaw sizing; factors influencing flaw detection probability; and performance of all participants with respect to recently developed ASME Section XI flaw detection performance demonstration requirements, and develops conclusions concerning ultrasonic inspection capability.

\section{Piping}

Joyce, J. A., U.S. Naval Academy, and Hackett, E. M., David Taylor Research Center, "Elastic - Plastic Characterization of a Cast Stainless Steel Pipe Elbow Material," NUREG/CR-5774, U.S. Nuclear Regulatory Commission, Washington, D.C., January 1992.

Tests conducted in Japan as part of the High Level Vibration Test (HLVT) program for reactor piping systems revealed fatigue crack growth in a cast stainless steel pipe elbow. The material tested was equivalent to ASME SA351-CF8M. The David Taylor Research Center (DTRC) was tasked to develop the appropriate material property data to characterize cyclic deformation, cyclic elastic-plastic crack growth and ductile tearing resistance in the pipe elbow material. It was found that the cast stainless steel was very resistant to ductile crack extension. J-R curves essentially followed a blunting behavior to very high $\mathrm{J}$ levels. Low cycle fatigue crack growth rate data obtained on this material using a cyclic $J$ integral approach was consistent with the high cycle fatigue crack growth rate and with a standard textbook correlation equation typical for this type of material. Evaluation of irack closure effects was essential to accurately determine the crack driving force for cyclic elastic-plastic crack growth in this material. SEM examination of several of the cyclic $J$ test fracture surfaces indicated that fatigue was the primary mode of fracture with ductile crack extension intervening only during the last few cycles of loading.

Kassir, M. K., et al., Brookhaven National Laboratory, "Analysis of Crack Initiation and Growth in the High Level Vibration Test at Tadotsu," NUREG/ CR-6078, U.S. Nuclear Regulatory Commission, Washington, D.C., August 1993.

The High Level Vibration Test dat? are used to assess the accuracy and usef ulness of current engineering methodologies for predicting crack initiation and growth in a cast stainless steel pipe elbow under complex, large amplitude loading. The data were obtained by testing at room temperature a large scale modified model of one loop of a PWR primary coolant system at the Tadotsu Engineering Laboratory in Japan. Fatigue crack initiation time is reasonably predicted by applying a modified local strain approach (Coffin-MasonGoodman equation) in conjunction with Miner's rule of cumulative damage. Three fracture mechanics methodologies are applicd to investigate the crack growth behavior observed in the hot leg of the model. These are: the $\Delta \mathrm{K}$ methodology (Paris law), $\Delta \mathrm{J}$ concepts and a recently developed limit load stress-range criterion. The report includes a discussion on the pros and cons of the analysis involved in each of the methods, the role played by the key parameters influencing the formulation and a comparison of the results with the actual crack growth behavior observed in the vibration test program. Some conclusions and recommendations for improvement of the methodologies are also provided.

Paul, D. D., et al., Battelle, Memorial Institute, "Evaluation and Refinement of Leak Rate Estimation Models," NUREG/CR-5128, U.S. Nuclear Regulatory Commission, Washington, D.C., April 1991.

Leak-rate estimation models are important elements in developing a leak-before-break methodology in piping integrity and safety analyses. Existing thermal hydraulic and crack-openingarea models used in current leak-rate estimations have been incorporated into a single computer code for leak-rate estimation. The code is called SQUIRT, which stands for Seepage Quantification of Upsets In Reactor Tubes. The SCUIRT program has been validated by comparing its thermal hydraulic predictions with the limited experimental data that have been published on two-phase flow through slits and cracks, and by comparing its crack-opening-area predictions with data from the Degraded Piping Program. In addition, leak-rate experiments were conducted 
to obtain validation data for a circumferential fatigue crack in a carbon steel pipe girth weld.

Wilkowski, G. M., et al., Battelle, "Short Cracks in Piping and Piping Welds. Semiannual Report for March - September 1990," NUREG/CR-4599, Vol. 1, No. 1, U.S. Nuclear Regulatory Commission, Washington, D.C., May 1991.

This is the first semiannual report of the U.S. Nuclear Regulatory Commission's Short Cracks in Piping and Piping Welds research program. The program began in March 1990 and will extend for 4 years. The intent of this program is to verify and improve fracture analyses for circumferentially cracked large-diameter nuclear piping with crack sizes typically used in leak-before-break analyses or in-service flaw evaluations. Only quasi-static loading rates are evaluated since the NRC's International Piping Integrity Research Group (IPIRG) program is evaluating the effects of seismic loading rates on cracked piping systems.

Additional efforts involve investigating phenomena discovered during the course of conducting the Degraded Piping program. These include the evaluation of the occurrence of unstable crack jumps in ferritic steels at LWR temperatures, and the occurrence of anisotropic fracture properties causing helicat crack growth. Both of these phenomena may affect the safety margins implicit in LBB analyses. Other investigations deal with the fracture behavior of bi-metallic welds, and improvements in crack opening area analyses used in LBB. Since much of the work in this program was just beginning during this first reporting period and progress is limited, a complete statement of work for the whole program is provided in this report.

Wilkowski, G. M., et al., Battelle, "Short Cracks in Piping and Piping Welds. Semiannual Report for October 1990 - March 1991," NUREG/CR-4599, Vol. 1, No. 2, U.S. Nuclear Regulatory Commission, Washington, D.C., April 1992.

This is the second semiannual report of the U.S. Nuclear Regulatory Commission's Short Cracks in Piping and Piping Welds research program. The program began in March 1990 and will extend for 4 years. The intent of this program is to verify and improve fracture analyses for circumferentially cracked large-diameter nuclear piping with crack sizes typically used in leak-before-break analyses or in-service flaw evaluations. Only quasi-static loading rates are evaluated since the NRC's International Piping Integrity Research Group (IPIRG) program is evaluating the effects of seismic loading rates on cracked piping systems. Progress for through-wall-cracked pipe involved: (1) conducting a 28-inch diameter stainless steel SAW and 4-inch diameter French TP316 experiments, (2) conducting a matrix of FEM analyses to determine GE/EPRI functions for short TWC pipe, (3) comparison of uncracked pipe maximum moments to various analyses and FEM solutions, and (4) development of a J-estimation scheme that includes the strength of both the weld and base metals. Progress for surfacecracked pipe involved: (1) conducting two experiments on 6-inch diameter (Sch. 40 and XXS) pipe with $d / t=0.5$ and $\theta / \pi=0.25$ cracks, (2) comparisons of the pipe experiments to Net-Section-Collapse predictions, and (3) modification of the SC.TNP and SC.TKP J-estimation schemes to include external surface cracks. high-temperature hardness testing appears to be a uscful screening critcria parameter for assessing the susceptibility of ferritic pipe to dynamic strain aging. For anisotropic fracture evaluations, it was found that only one of five ferritic pipes had the low toughness direction in a helical direction, the rest had low toughness in the axial direction. For crack-opening area analyses, predictive capabilities were expanded so that load versus crack opening can be calculated from the LBB.NRC, GE/EPRI, LBB.GE, LBB.ENG, and Tada/Paris analyses. These include loading due to tension, bending, and combined tension and bending. The LBB.ENG analysis was also modified to account for the weld and base metals strengths. Elastic FEA showed that for pressure loading, a crack close to a terminal end (i.e., a nozzle) will have lower crack opening due to restraint of the induced bending. This could affect LBB analyses.

Wilkowski, G. M., et al., Battelle, "Short Cracks in Piping and Piping Welds. Semiannual Report for April - September 1991," NUREG/CR-4599, Vol. 2, No. 1, U.S. Nuclear Regulatory Commission, Washington, D.C., September 1992.

This is the third semiannual report of the U.S. Nuclear Regulatory Commission's Short Cracks in Piping and Piping Welds research program. This 4-year program began in March 1990. The overall objective of this program is to verify and improve fracture analyses for circumferentially cracked large-diameter nuclear piping with crack sizes typically used in leak-before-break analyses or inservice flaw evaluations.

Wilkowski, G. M., et al., Battelle, "Short Cracks in Piping and Piping Welds. Semiannual Report for October 1991 - March 1992," NUREG/CR-4599, Vol. 2, 
No. 2, U.S. Nuclear Regulatory Commission, Washington, D.C., May 1992.

This is the fourth semiannual report of the U.S. Nuclear Regulatory Commission's Short Cracks in Piping and Piping Welds research program. This 4-year program began in March 1990. The overall objective of this program is to verify and improve fracture analyses for circumferentially cracked large-diameter nuclear piping with crack sizes typically used in leak-before-break analyses or in-service flaw evaluations. Progress during this reporting period involved: (1) completing two through-wall-cracked pipe experiments and supplementary material property data, (2) an internal circumferential surface-cracked pipe experiment was completed which showed that the $\mathrm{R} / \mathrm{t}$ effects on the Net-Section-Collapse predicted loads for surface-cracked pipe to be independent of crack size, (3) the anisotropy investigation showed that pipe dimensions may be as important in determining the out-of-plane crack growth angle as the anisotropy of the toughness, (4) we initiated a probabilistic analysis of LBB to assess the potential changes in the leakage detection criteria in NRC Reg Guide 1.45, and (5) other efforts involved a sensitivity study on the effect of thermal aging of cast stainless steel on the moment-carrying capacity of the pipe as a function of time.

\section{Pressure Vessel Steels}

Dally, J. W., University of Maryland, et al., "The Influence of Precompression on the Lower-Bound Initiation Toughness of A 533 B Reactor Grade Steel," NUREG/CR-5847, U.S. Nuclear Regulatory Commission, Washington, D.C., May 1992.

This report first describes the test method employing a precompressed round bar subjected to impact loading to initiate a cleavage fracture. The procedure to convert strain measurement into dynamic initiation toughness $\mathrm{K}_{\mathrm{Id}}$ is described. Also, the results of a fractographic analysis are correlated with the features observed on the strain-time traces, and techniques used to distinguish initiation by either cleavage or ductile tearing are presented.

Irwin, G. R., and Zhang, X. J., University of Maryland, "Gradient Study of a Large Weld Joining Two Forged A 508 Shells of the Midland Reactor Vessel," NUREG/CR-5867, U.S. Nuclear Regulatory Commissicn, Washington, D.C., June 1992.

The low-carbon welds (WF67 and WF70) in the slab examined contained no abnormalities that would indicate fracture behavior different from that observed in bulk-material fracture tests. The A 508 material in the HAZ region, very close to the welds, contains small $(3 \mathrm{~mm})$ regions adjacent to each layer of weld runs where grain coarsening and hardness elevation suggest reduction of cleavage initiation toughness. The degree of severity is largest where this local region coincides with a local elevation of carbide density in the $A$ 508 material. The A $508 \mathrm{HAZ}$ region adjacent to the topmost weld run may be the region most likely to assist cleavage-fractl're initiation because of its location: close to a free surface, small cracks, and the HAZ region beneath the cladding. It was noted that the small cracks under the cladding have the appearance of prior austenite grain boundary separations that connect to austenite grain boundaries in the cladding. The extreme hardness of a narrow layer of cladding at the fusion boundary may be of interest in further studies of cladding toughness.

Nanstad, R. K., et al., Oak Ridge National Laboratory, "Chemical Composition and $\mathrm{R}^{\mathrm{T}} \mathrm{NDT}_{\mathrm{T}}$ Determinations for Midland Weld WF-70," NUREG/CR-5914, U.S. Nuclear Regulatory Commission, Washington, D.C., December 1992.

The Heavy-Section Steel Irradiation Program Tenth Irradiation Series has the objective to investigate the effects of radiation on the fracture toughness of the low-upper-shelf submerged-arc welds (B\&W designation WF-70) in the reactor pressure vessel of the canceled Midland Unit 1 nuclear plant. This report discusses determination of variations in chemical composition and reference temperature $\mathrm{RT}_{\mathrm{NDT}}$ throughout the welds. Specimens were machined from different sections and through thickness locations in both the beltline and nozzle course welds. The nil-ductility transition temperatures ranged from -40 to $-60^{\circ} \mathrm{C}\left(-40\right.$ and $\left.-76^{\circ} \mathrm{F}\right)$ while the $\mathrm{RT}_{\mathrm{NDT}} \mathrm{s}$, controlled by the Charpy behavior, varied from -20 to $37^{\circ} \mathrm{C}\left(-4\right.$ to $\left.99^{\circ} \mathrm{F}\right)$. The upper-shelf energies varied from 77 to $108 \mathrm{~J}$ ( 57 to $80 \mathrm{ft}-\mathrm{lb}$ ). The combined data revealed a mean $41-\mathrm{J}(30-\mathrm{ft}-\mathrm{lb})$ temperature of $-8^{\circ} \mathrm{C}\left(17^{\circ} \mathrm{F}\right)$ with a mean upper-shelf energy of $88 \mathrm{~J}(65 \mathrm{ft}-\mathrm{lb})$. The copper contents range from 0.21 to $0.34 \mathrm{wt} \%$ in the beltline weld and from 0.37 to $0.46 \mathrm{wt} \%$ in the nozzle course weld. Atom probe field ion microscope analyses indicated substantial depletion of copper in the matrix but no evidence of copper clustering. Statistical analyses of the Charpy and chemical composition results as well as interpretation of the ASME procedures for $\mathrm{RT}_{\mathrm{NDT}}$ determination are discussed. 


\section{Radiation Embrittlement}

Chopra, O. K., Argonne National Laboratory, and Rosinski, S. T., Sandia National Laboratories, "Radiation Embrittlement of the Neutron Shield Tank from the Shippingport Reactor," NUREG/CR-5748, U.S. Nuclear Regulatory Commission, Washington, D.C., October 1991.

The irradiaiinn embrittlement of Shippingport neutron shield tank (NST) material (A212-B) has been characterized. Irradiation increases the Charpy transition temperature (CTT) by $23-28^{\circ} \mathrm{C}$ $\left(41-50^{\circ} \mathrm{F}\right)$ and decreases the upper-shelf energy. The shift in CTT is not as severe as that observed in high-flux isotope reactor (HFIR) surveillance samples. However, the actual value of the CTT is higher than that for the HFIR data. The increase in yield stress is $51 \mathrm{MPa}$ (7.4 ksi), which is comparable to HFIR data. The NST material is weaker in the transverse than in the longitudinal orientation. Some effects of position across the thickness of the wall are also observed; the CTT shift is slightly greater for specimens from the inner region of the wall. Annealing studies indicate complete recovery from embrittlement after $1 \mathrm{~h}$ at $400^{\circ} \mathrm{C}\left(752^{\circ} \mathrm{F}\right)$. Although the weld metal is significantly tougher than the base metal, the shifts in CTT are comparable. The shifts in CTT for the Shippingport NST are consistent with the test and Army reactor data for irradiations at $<232^{\circ} \mathrm{C}$ $\left(<450^{\circ} \mathrm{F}\right)$ and show very good agreement with the results for HFIR A212-B stcel irradiated in the Oak Ridge Research React (ORR). The effects of irradiation temperature, fluence rate, and neutron flux spectrum are discussed. The results indicate that fluence rate has no effect on radiation embrittlement at rates as low as $2 \times 10^{8}$ $\mathrm{n} / \mathrm{cm}^{2} / \mathrm{s}$ and at the low operating temperatures of the Shippingport NST, i.e., $55^{\circ} \mathrm{C}\left(130^{\circ} \mathrm{F}\right)$. This suggests that the accelerated embrittlement of HFIR surveillance samples is most likely due to the relatively higher proporion of thermal neutrons in the HFIR spectrum compared to that for the test reactors.

Hawthorne, J. R., Materials Engineering Associates, Inc., "Accelerated Irradiation Test of Gundremmingen Reactor Vessel Trepan Material," NUREG/ CR-5891, U.S. Nuclear Regulatory Commission, Washington, D.C., August 1992.

Initial mechanical properties tests of beltline Material trepanned from the decommissioned KRB-A pressure vessel and archive material irradiated in the UBR test reactor revealed a major anomaly in relative radiation embrittlement sensitivity. Poor correspondence of material behavior in test vs power reactor environments was observed for the weak test orientation (ASTM L-C) whereas correspondence was good for the strong orientation (ASTM C-L). To resolve the anomaly directly, Charpy-V specimens from a low (essentially-nil) fluence region of the vessel were irradiated together with archive material at $279^{\circ} \mathrm{C}$ in the UBR test reactor. Properties tests before UBR irradiation revealed a significant difference in 41-J transition temperature and upper shelf energy level between the materials. However, the materials exhibited essentially the same radiation embrittlement sensitivity (both orientations), proving that the anomaly is not due to a basic difference in material irradiation resistances. Possible causes of the original anomaly and the significance to NRC Regulatory Guide 1.99 are discussed.

Iskander, S. K., et al., Oak Ridge National Laboratory, "Results of Crack Arrest Tests on Two Irradiated High Copper Welds," NUREG/CR-5584, U.S. Nuclear Regulatory Commission, Washington, D.C., December 1990.

The objective of this study was to determine the effect of neutron irradiation on the shift and shape of the lower-bound curve to crack-arrest data. Two submerged-arc welds with copper contents of 0.23 and $0.31 \mathrm{wt} \%$ were commercially fabricated in 220-mm-thick plate. Crack-arrest specimens fabricated from these welds were irradiated at a nominal temperature of $288^{\circ} \mathrm{C}$ to an average fluence of $1.9 \times 10^{19}$ neutrons $/ \mathrm{cm}^{2}(\mathrm{E}>$ $1 \mathrm{MeV})$. Evaluation of the results shows that the neutron-irradiation-induced crack arrest toughness temperature shift is about the same as the Charpy V-notch impact-temperature shift at the 41-J energy level. The shape of the lower bound curves (for the range of test temperatures covered) did not seem to have been altered by irradiation compared to those of the ASME $\mathrm{K}_{\mathrm{Ia}}$ curve.

Kampmann, R., Institute For Materials Research, et al., "SANS Investigation of Low Alloy Stcels in Neutron Irradiated, Anncaled, and Reirradiated Conditions,".NUREG/CR-5926, U.S. Nuclear Regulatory Commission, Washington, D.C., February 1993.

Small Angle Neutron Scattering (SANS) experiments were made on several low alloy steels and submerged-arc welds prototypic of nuclear reactor vessel construction. The objective was the characterization of radiation-enhanced and/or radiation-induced precipitation contributing to mechanical property changes observed in tensile and notch ductility tests of the materials. The materials were irradiated in the UBR Test Reactor under closely controlled conditions. A portion of the 
samples were examined in the $288^{\circ} \mathrm{C}$ irradiated (I) condition; others were examined in the postirradiation annealed (IA) condition and in the $288^{\circ} \mathrm{C}$ reirradiated (IAR) condition. Experimental variables included material composition (primarily $\% \mathrm{Cu}, \% \mathrm{P}, \% \mathrm{Ni}$ content), postirradiation annealing temperature $\left(454^{\circ} \mathrm{C}\right.$ and $\left.399^{\circ} \mathrm{C}\right)$ reirradiation fluence level, and neutron-fluence rate $\left(\sim 0.08,0.7\right.$, and $\left.9 \times 10^{12} \mathrm{n} / \mathrm{cm}^{2}-\mathrm{s}^{-1}, \mathrm{E}>1 \mathrm{MeV}\right)$. The apparent influence of the described variables on the size, number density, and composition of copper-rich precipitates was the primary focus of the SANS analyses. SANS observations are related to measured notch ductility and tensile property changes, with a view toward mechanistic explanation of the observed mechanical property trends for I, IA, and IAR conditions.

Nanstad, R. K. and Berggren, R. G., Oak Ridge National Laboratory, "Irradiation Effects on Charpy Impact and Tensile Properties of Low Upper Shelf Welds, HSSI Series 2 and 3," NUREG/CR-5696, U.S. Nuclear Regulatory Commission, Washington, D.C., August 1991.

The objective of the Second and Third Irradiation Series was to investigate the effects of irradiation on the ductile fracture toughness of seven commercially fabricated, low upper-shelf welds. All seven submerged-arc welds were fabricated with copper-coated wire and Linde 80 flux and had average bulk-copper contents from 0.21 to $0.42 \%$ with nickel levels of about $0.6 \%$. In addition to the fracture toughness specimens which were irradiated at nominally $288^{\circ} \mathrm{C}$, Charpy V-notch and tensile specimens were included in the capsules at available locations which were subject to wide variations in irradiation temperature and fluence. This report presents analyses of the Charpy impact and tensile test data. Analyses revealed a dependence of yield strength on irradiation temperature of $-1.1 \mathrm{MPa} /{ }^{\circ} \mathrm{C}$, while the Charpy impact energy dependencies were about $-0.5^{\circ} \mathrm{C} /{ }^{\circ} \mathrm{C}$ for transition temperature shift and $-0.06 \mathrm{~J} /{ }^{\circ} \mathrm{C}$ for upper-shelf decrease. After adjustment to an irradiation temperature of $288^{\circ} \mathrm{C}$ and normalization to a fluence of $8 \times 10^{18}$ neutrons $/ \mathrm{cm}^{2}(E>1$ $\mathrm{MeV})$, the Charpy transition temperature shifts ranged from 59 to $123^{\circ} \mathrm{C}$ while the upper-shelf energies ranged from 58 to $79 \mathrm{~J}$.

Nanstad, R. K., et al., Oak Ridge National Laboratory, "Irradiation Effects on Fracture Toughness of Two High-Copper Submerged-Arc Welds, HSSI Series 5, Main Report and Appendices A, B, C, and D," NUREG/CR-5913, Vol. 1, U.S. Nuclear Regulatory Commission, Washington, D.C., October 1992.
The Fifth Irradiation Series in the Heavy-Section Steel Irradiation Program obtained a statistically significant fracture toughness data base on two high-copper $(0.23$ and $0.31 \mathrm{wt} \%)$ submerged-arc welds to determine the shift and shape of the $K_{I c}$ curve as a consequence of irradiation. Compact specimens with thicknesses to $101.6 \mathrm{~mm}$ (4 in.) in the irradiated condition and $203.2 \mathrm{~mm}$ (8 in.) in the unirradiated condition were tested, in addition to Charpy impact, tensile, and drop-weight specimens. Irradiations were conducted at a nominal temperature of $288^{\circ} \mathrm{C}$ and an average fluence of $1.5 \times 10^{19} \mathrm{n} / \mathrm{cm}^{2}(\mathrm{E}>1 \mathrm{McV})$. The Charpy 41-J temperature shifts are about the same as the corresponding drop-weight NDT temperature shifts. The irradiated welds cxhibited substantial numbers of cleavage pop-ins. Mean curve fits using two-parameter (with fixed intercept) nonlinear and linearized exponential regression analyses revealed that the fracture toughness $100 \mathrm{MPa} \sqrt{\mathrm{m}}$ shifts exceeded the Charpy 41-J shifts for both welds. Analyses of curve shape changes indicated decreases in the slopes of the fracture toughness curves, especially for the higher copper weld. Weibull analyses were performed to investigate development of lower bound curves to the data, including the use of a variable $\mathrm{K}_{\min }$ parameter which affects the curve shape.

Nanstad, R. K., et al., Oak Ridge National Laboratory, "Irradiation Effects on Fracture Toughness of Two High-Copper Submerged-Arc Welds, HSSI Series 5, Appendices E and F," NUREG/CR-5913, Vol. 2, U.S. Nuclear Regulatory Commission, Washington, D.C., October 1992.

The Fifth Irradiation Series in the Heavy-Section Steel Irradiation Program obtained a statistically significant fracture toughness data base on two high-copper ( 0.23 and $0.31 \mathrm{wt} \%)$ submerged-arc welds to determine the shift and shape of the $\mathrm{K}_{\mathrm{Ic}}$ curve as a consequence of irradiation. Compact specimens with thicknesses to $101.6 \mathrm{~mm}$ (4 in.) in the irradiated condition and $203.2 \mathrm{~mm}$ (8 in.) in the unirradiated condition were tested, in addition to Charpy impact, tensile, and drop-weight specimens. Irradiations were conducted at a nominal temperature of $288^{\circ} \mathrm{C}$ and an average fluence of $1.5 \times 10^{19} \mathrm{n} / \mathrm{cm}^{2}(\mathrm{E}>1 \mathrm{MeV})$. The Charpy 41-J temperature shifts are about the same as the corresponding drop-weight NDT temperature shifts. The irradiated welds exhibited substantial numbers of cleavage pop-ins. Mean curve fits using two-parameter (with fixed intercept) nonlinear and linearized exponential regression analyses revealed that the fracture toughness 100 $\mathrm{MPa} \sqrt{\mathrm{m}}$ shifts exceeded the Charpy $41-\mathrm{J}$ shifts 
for both welds. Analyses of curve shape changes indicated decreases in the slopes of the fracture toughness curves, especially for the higher copper weld. Weibull analyses were performed to investigate development of lower bound curves to the data, including the use of a variable $\mathrm{K}_{\min }$ parameter which affects the curve shape.

Stallmann, F. W., et al., Oak Ridge National Laboratory, "PR-EDB Power Reactor Embrittlement Data Base, Version 1, Program Description," NUREG/ CR-4816, U.S. Nuclear Regulatory Commission, Washington, D.C., July 1991.

Data concerning radiation embrittlement of pressure vessel steels in commercial power reactors have been collected from available surveillance reports. The purpose of this NRC-sponsored program is to provide the technical bases for voluntary consensus standards, regulatory guides, standard review plans, and codes. The data can also be used for the exploration and verification of embrittlement prediction models. The data files are given in DBASE III PLUS format and can be accessed with any personal computer using the DOS operating system. Menu-driven software is provided for easy access to the data including curve fitting and plotting facilities. This software has drastically reduced the time and effort for data processing and evaluation compared to previous data bases. The current version of the Power Reactor Embrittlement Data Base (PR-EDB) lists the test results of 117 base materials (plates and forgings), 85 welds, and 88 heat-affectedzone materials that were irradiated in 241 capsules of 82 reactors. Many capsules also contained correlation materials (standard reference materials, SRMs) from the ASTM plate and two HSST plates (01 and 02). Material from the Humboldt Bay reactor was used as an SRM for some General Electric reactors. The Electric Power Research Institute (EPRI), reactor vendors, and utilities have provided back-up quality assurance checks of the PR-EDB.

Stoller, R. E., Oak Ridge National Laboratory, "Modeling the Influence of Irradiation Temperature and Displacement Rate on Radiation-Induced Hardening in Ferritic Steels," NUREG/CR-5859, U.S. Nuclear Regulatory Commission, Washington, D.C., July 1992.

The influence of irradiation temperature and displacement rate have been investigated using a model based on the reaction rate theory description of re diation damage. This theory was developed primarily for the investigation of relatively high-temperature, high-dose radiation effects such as void swelling and irradiation creep. Before applying that theory to the much lower temperature and dose regimes characteristic of light water reactor pressure vessels and support structures, it is necessary to examine the assumptions made in formulating the theory. The major simplifying assumption that has commonly been made is that the interstitial and vacancy concentrations reach a quasi-steady state condition rapidly enough that the steady state concentrations can be used in calculating the observable radiation effects. The results presented here indicate that the assumption of steady state point defect concentrations is not valid for temperatures much below the light water reactor pressure vessel operating temperature of about $288^{\circ} \mathrm{C}$. At lower temperatures, the time required for the point defect concentrations to reach steady state can exceed an operating reactor's lifetime. Even at $288^{\circ} \mathrm{C}$, the point defect transient time can be long enough to influence the interpretation of irradiation experiments done in materials test reactors at accelerated damage rates. Based on the insights obtained with the simple models of point defect evolution, a more detailed model was developed that incorporates an explicit description of point defect clustering. These clusters are potentially responsible for the fraction of the radiation-induced hardening that is attributed to the so-called "matrix defect." The model considers both interstitial and vacancy clustering. The former are treated as Frank loops while the latter are treated as microvoids. The point defect clusters can be formed either directly in the displacement cascade or by diffusive encounters between free point defects. The results of molecular dynamics simulation studies are used to provide guidance for the clustering parameters. The hardening due to point defect clusters was calculated using a simple dislocation barrier model. The results indicate that both interstitial and vacancy clusters can give rise to significant hardening. The relative importance of each cluster type is shown to be a function of irradiation temperature and displacement rate.

\section{Reactor Pressure Vessel Integrity Assessments}

Cheverton, R. D., Oak Ridge National Laboratory, et al., "Review of Reactor Pressure Vessel Evaluation Report for Yankee Rowe Nuclear Power Station," NUREG/CR-5799, U.S. Nuclear Regulatory Commission, Washington, D.C., March 1992.

The Yankee Atomic Electric Company (YAEC) has performed an Integrated Pressurized Thermal Shock (IPTS)-type evaluation of the Yankee 
Rowe reactor pressure vessel in accordance with the PTS Rule (10 CFR 50.61) and U.S. Regulatory Guide 1.154. The Oak Ridge National Laboratory (ORNL) reviewed the YAEC document and performed an independent probabilistic fracturemechanics analysis. The review included a comparison of the Pacific Northwest Laboratory and the ORNL probabilistic fracture-mechanics codes (VISA-II and OCA-P, respectively). The review identified minor errors and one significant difference in philosophy. Also, the two codes have a few dissimilar peripheral features. Aside from these differences, VISA-II and OCA-P are very similar and with errors corrected and when adjusted for the difference in the treatment of fracture toughness distribution through the wall, yield essentially the same value of the conditional probability of failure. The ORNL independent evaluation indicated $\mathrm{RT}_{\mathrm{NDT}}$ values considerably greater than those corresponding to the PTSRule screening criteria and a frequency of failure substantially greater than that corresponding to the "primary acceptance criterion" in U.S. Regulatory Guide 1.154. Time constraints, however, prevented as rigorous a treatment as the situation deserves. Thus, these results are very preliminary.

Dickson, T. L., Oak Ridge National Laboratory, "Generic Analysis for Evaluation of Low Charpy Upper-shelf Energy Effects on Safety Margins Against Fracture of Reactor Pressure Vessel Materials," NUREG/CR-6023, U.S. Nuclear Regulatory Commission, Washington, D.C., July 1993.

Appendix G to $10 \mathrm{CFR}$ Part 50 requires that reactor pressure vessel beltline materials maintain Charpy upper-shelf energies of no less than 50 $\mathrm{ft}-\mathrm{lb}$ during the plant operating life, unless it is demonstrated in a manner approved by the $\mathrm{Nu}$ clear Regulatory Commission (NRC), that lower values of Charpy upper-shelf energy provide margins of safety against fracture equivalent to those in Appendix G to Section XI of the ASME Code. Analyses based on acceptance criteria and analysis methods adopted in the ASME Code Case $\mathrm{N}-512$ are described herein. Additional information on material properties was provided by the NRC, Office of Nuclear Regulatory Research, Materials Engineering Branch. These cases, specified by the NRC, represent generic applications to boiling water reactor and pressurized water reactor vessels. This report is designated as HSST Report No. 140.

Dickson, T. L., et al., Oak Ridge National Laboratory, "Pressurized Thermal Shock Probabilistic Fracture Mechanics Sensitivity Analysis for Yankee Rowe
Reactor Pressure Vessel," NUREG/CR-5782, U.S. Nuclear Regulatory Commission, Washington, D.C., August 1993.

The Nuclear Regulatory Commission (NRC) requested Oak Ridge National Laboratory (ORNL) to perform a pressurized-thermal-shock (PIS) probabilistic fracture mechanics (PFM) sensitivity analysis for the Yankee Rowe reactor pressure vessel, for the fluences corresponding to the end of operating cycle 22, using a specific small-break-loss-ofcoolant transient as the loading condition. Regions of the vessel with distinguishing features were to be treated individually-upper axial weld, lower axial weld, circumferential weld, upper plate spot welds, upper plate regions between the spot welds, lower plate spot welds, and the lower plate regions between the spot welds. The fracture analysis methods used in the analysis of through-clad surface flaws were those contained in the established OCA-P computer code, which was developed during the Integrated Pressurized Thermal Shock (IPTS) Program. The NRC request specified that the OCA-P code be enhanced for this study to also calculate the conditional probabilities of failure for subclad flaws and embedded flaws. The results of this sensitivity analysis provide the NRC with (1) data that could be used to assess the relative influence of a number of key input parameters in the Yankee Rowe PTS analysis and (2) data that can be used for readily determining the probability of vessel failure once a more accurate indication of vessel embrittlement becomes available. This report is designated as HSST report No. 117.

\section{Risk-Based Inspection}

American Society of Mechanical Engineers, "Risk Based Inspection - Development of Guidelines. General Document," NUREG/GR-0005, Vol. 1, U.S. Nuclear Regulatory Commission, Washington, D.C., February 1992.

Inservice inspection can play a significant role in minimizing equipment and structural failures. For many industrial applications, requirements for inservice inspection are based upon prior experience or engineering judgment, or are nonexistent. Most requirements or guidelines for these inspections are based on engineers' qualitative judgment, and only implicitly take into account the probability of failure of a component under its operation and loading conditions, and the consequence of such failure, if it occurs. This document recommends appropriate methods for establishing a risk-based inspection program for any facility or structural system. The process involves four major steps: defining the system; performing a qualitative risk assessment; using this to do a 
quantitative risk analysis; and developing an inspection program for components and structural elements using probabilistic engineering methods. A companion document will detail specific risk-based techniques for the inspection of components of LWR nuclear power plants, applying methodology set out in Volume 1.

American Society of Mechanical Engineers, "Risk Based Inspection - Development of Guidelines. Light Water Reactor (LWR) Nuclear Power Plant Components," NUREG/GR-0005, Vol. 2, Part 1, U.S. Nuclear Regulatory Commission, Washington, D.C., July 1993.

Effective inservice inspection programs can play a significant role in minimizing equipment and structural failures. Most of the current inservice inspection programs for light water reactor (LWR) nuclear power plant components are based on experience and engineers' qualitative judgment. These programs include only an implicit consideration of risk, which combines the probability of failure of a component under its operation and loading conditions and the consequences of such failure, if it occurs. This document recommends appropriate methods for establishing a risk-based inspection program for LWR nuclear power plant components. The process has been built from a general methodology (Volume 1) and has been expanded to involve five major steps: defining the system; evaluating qualitative risk assessment results; using this and information from plant probabilistic risk assessments to perform a quantitative risk analysis; selecting target failure probabilities; and developing an inspection program for components using economic decision analysis and structural reliability assessment methods. Included: extensive bibliography. Companion Volume 2 - Part 2 document will recommend risk-based inspection program for consideration by Section XI of the ASME Boiler and Pressure Vessel Code.

\section{Stainless Steel Sensitization}

Atteridge, D. G., and Cedeno, C. A., Oregon Graduate Institute of Science \& Technology, "Continuous Cooling Thermal Cycle Effects on Sensitization in Stainless Steel," NUREG/GR-0002, U.S. Nuclear Regulatury Commission, Washington, D.C., September 1991.

Work for this study was directed towards quantifying sensitization development (defined as grain boundary chromium depletion) in high carbon Type 304 and 316 stainless steel (SS) subjected to linear heating to a given peak temperature followed by linear cooling through the sensitization develop- ment temperature range. The major variables investigated included: (1) heating rate; (2) peak temperature; (3) holding time at peak temperature; and (4) cooling rate. Change in sensitization was tracked using the electrochemical potentiokinetic reactivation (EPR) iest. Continuous heating/cooling cycles were performed using a furnace or using a thermal cycle simulation machine (Glecble). Sensitization was found to increase with increasing peak temperature until a "critical" peak temperature was reached. Sensitization was very low for all samples heated above this critical peak temperature. The critical peak temperature was $900^{\circ} \mathrm{C}$ for highcarbon $(0.06 \mathrm{wt} \%) 304$ and varied from 950 to $1000^{\circ} \mathrm{C}$ for high-carbon $(0.06 \mathrm{wt} \%) 316 \mathrm{SS}$. Sensitization increased with decreasing cooling rate and appeared to decrease with increasing heating rate. The slowest heating rate used was equal to the fastest cooling rate tested. Results are discussed in terms of grain boundary chromium carbide nucleation and precipitation, and chromium depletion.

Atteridge, D. G., et al., Oregon Graduate Institute of Science \& Technology, "Measurement and Modeling of Sensitization Development in Stainless Steels as a Function of Thermomechanical Processing," NUREG/GR-0004, U.S. Nuclear Regulatory Commission, Washington, D.C., November 1992.

An analytical model has been developed for predicting thermomechanical effects on the development of grain boundary chromium depletion in austenitic stainless steel as a first step in predicting intergranular stress corrosion cracking susceptibility. Model development and validation is based on sensitization development analysis of over 30 Type 316 and 304 stainless steel heats. The data base included analysis of deformation effects on resultant sensitization development. Continuous cooling sensitization behavior is examined and modeled with and without strain. Gas tungsten arc girth pipe weldments are also characterized by experimental measurements of heat affected zone temperatures, strains and sensitization during/after each pass; pass by pass thermal histories are also predicted. The model is then used to assess pipe chemistry changes on chromium depletion changes.

Bruemmer, S. M., and Atteridge, D. G., Oregon Graduate Institute of Science \& Technology, "Quantitative Measurement and Modeling of Sensitization Development in Stainless Steel," NUREG/ GR-0001, U.S. Nuclear Regulatory Commission, Washington, D.C., September 1992

The state-of-the-art to quantitatively measure and model sensitization development in austenitic stainless steels is assessed and critically analyzed. A 
modeling capability is evolved and validated using a diverse experimental data base. Quantitative predictions are demonstrated for simple and complex thermal and thermomechanical treatments. Commercial stainless steel heats ranging from high-carbon Type 304 and 316 to low-carbon Type 304L and $316 \mathrm{~L}$ have been examined including many heats which correspond to extra-low-carbon, nucleargrade compositions. Within certain limits the clectrochemical potentiokinetic reactivation (EPR) test was found to give accurate and reproducible measurements of the degrec of sensitization (DOS) in Type 304 and 316 stainless steels. EPR test results are used to develop the quantitative data base and evolve/validate the quantitative modeling capability. This thesis represents a first step to evolve methods for the quantitative assessment of structural reliability in stainless steel components and weldments. Assessments will be based on componentspecific information concerning material characteristics, fabrication history and service exposure. Methods will enable fabrication (e.g., welding and repair welding) procedures and material aging effects to be evaluated and ensure adequate cracking resistance during the service lifetime of reactor components. This work is being conducted by the Oregon Graduate Institute with interactive input from personnel at Pacific Northwest Laboratory.

Simmons, J. W., Oregon Graduate Institute of Science \& Technology, "Effect of Prior Deformation on Sensitization Development in Stainless Steel During Continuous Cooling," NUREG/GR-0003, U.S. Nuclear Regulatory Commission, Washington, D.C., September 1991.

High-carbon Type 316 stainless steel (SS) specimens were subjected to linear continuous cooling in a computer-controlled Gleeble thermal simulator. The degree of sensitization (DOS) was quantitatively measured using the electrochemical potentiokinetic reactivation (EPR) test. Sensitization values for the thermal cycles employed in the investigation were predicted using Bruemmer's SSDOS sensitization prediction model. Prior deformation significantly enhanced the rate of DOS development in the Type 316 SS material. The DOS increased with increasing amounts of prior strain and decreasing cooling rates. Sensitization response was also sensitive to peak cycle temperatures. Continuous cooling sensitization development occurred primarily in the critical temperature range between about 900 and $750^{\circ} \mathrm{C}$. Peak cycle temperatures above $1000^{\circ} \mathrm{C}$ retarded sensitization development during subse- quent continuous cooling. Strain recovery at elevated temperatures played an important role in reducing the effectiveness of prior deformation in accelerating sensitization kinetics. Due to the effects of recovery, in certain cases, prior strain values of $20 \%$ werc only as effective as $10 \%$ in increasing the rate of sensitization development. Limited transgranular carbide precipitation was observed in $20 \%$ prior strain samples but was not a significant factor in the present work. The SSDOS model consistently over predicted DOS development regardless of material condition.

\section{Thermal Aging (Cast Stainless Steel)}

Chopra, O. K., Argonne National Laboratory, "Estimation of Fracture Toughness of Cast Stainless Stecls During Thermal Aging in LWR Systems," NUREG/ CR-4513, U.S. Nuclear Regulatory Commission, Washington, D.C., June 1991.

A procedure and correlations are presented for predicting the change in fracture toughness of cast stainless steel components due to thermal aging during service in light water reactors (LWRs) at $280-330^{\circ} \mathrm{C}\left(535-625^{\circ} \mathrm{F}\right)$. The fracture toughness J-R curve and Charpy-impact energy of aged cast stainless steels are estimated from known material information. Fracture toughness of a specific cast stainless steel is estimated from the extent and kinetics of thermal embrittlement. The extent of thermal embrittlement is characterized by the room-temperature "normalized" Charpy-impact energy. A correlation for the extent of embrittlement at "saturation," i.e., the minimum impact energy that would be achieved for the material after long-term aging, is given in terms or a material parameter, $\phi$, which is determined from the chemical composition. The fracture toughness J-R curve for the material is then obtained from correlations between room-temperature Charpy-impact energy and fracture toughness parameters. Fracture toughness as a function of time and temperature of reactor service is estimated from the kinetics of thermal embrittlemen', which is determined from chemical composition. A common "lower-bound" J-R curve for cast stainless steels with unknown chemical composition is also defined for a given material specification, ferrite content, and temperature. Examples for estimating impact strength and fracture toughness of cast stainless steel components during reactor service are described. 
Chopra, O. K. and Chung, H. M., Argonne National Laboratory, "Long-Term Embrittlement of Cast Duplex Stainless Steels in LWR Systems," NUREG/ CR-4744, Vol. 4, No. 1, U.S. Nuclear Regulatory Commission, Washington, D.C., May 1991.

This progress report summarizes work performed by Argonne National Laboratory on long-term embrittlement of cast duplex stainless steels in LWR systems during the six months from October 1988 to March 1989. Charpy-impact data are presented for several heats of cast stainless stcel aged at temperatures between 320 and $450^{\circ} \mathrm{C}$ for times up to $30,000 \mathrm{~h}$. Thermal aging decreases impact energy and shifts transition curves to higher temperatures. A saturation effect is observed for room-temperature impact energy and upper-shelf energy. Charpy data are analyzed to obtain the activation energy of the kinetics of embrittlement. The results suggest that the activation energy of embrittlement is not constant in the temperature range of $290-400^{\circ} \mathrm{C}$, but increases as temperature decreases. A correlation is presented for estimating the extent of embrittlement of cast stainless steels from known material parameters. The degradation in mechanical properties can be reversed by annealing the embrittled material for $1 \mathrm{~h}$ at $550^{\circ} \mathrm{C}$ and then water quenching.

Chopra, O. K., et al., Argonne National Laboratory, "Long-Term Embrittlement of Cast Duplex Stainless Steels in LWR Systems, Semiannual Report for April - September 1989," NUREG/CR-4744, Vol. 4, No. 2, U.S. Nuclear Regulatory Commission, Washington, D.C., June 1991.

This progress report summarizes work performed by Argonne National Laboratory on long term thermal embrittlement of cast duplex stainless steels in LWR systems during the six months from April to September 1989. Tensile and fracture toughness data are presented for several heats of cast stainless steel that were aged up to $30,000 \mathrm{~h}$ at temperatures of $290-450^{\circ} \mathrm{C}$. The results indicate that thermal aging increases the tensile stress and decreases the fracture toughness of the materials. In general, C-3 steels are the least sensitive to thermal aging embrittlement and C-8M steels are the most sensitive. The increase in flow stress of fully aged cast stainless steels is $\approx 10 \%$ for CF-3 steels and $\approx 20 \%$ for CF-8 and CF-8M steels. The fracture toughness $J_{I c}$ and average tearing modulus for heats that are sensitive to thermal aging (e.g., CF-8M stecls) are as low as $\approx 90 \mathrm{~kJ} / \mathrm{m}^{2}$ and $\approx 60$, respectively. Correlations are presented for estimating the increase in flow stress of the steels from data for the kinetics or thermal embrittlement.

Chopra, O. K. and Bush, L. Y., Argonne National Laboratory, "Long-Term Embrittlement of Cast Duplex Stainless Steels in LWR Systems. Semiannual Report for October 1989 - March 1990," NUREG/ CR-4744, Vol. 5, No. 1, U.S. Nuclear Regulatory Commission, Washington, D.C., July 1991.

This progress report summarizes work performed by ANL on long-term thermal embrittlement of cast duplex stainless steels in LWR systems during the six months from October 1989 to March 1990. The results from Charpy-impact tests and microhardness measurements of the ferrite phase for several heats of cast stainless steel aged up to $30,000 \mathrm{~h}$ at $290-400^{\circ} \mathrm{C}$ are analyzed to establish the kinetics of thermal embrittlement. Correlations are presented for predicting the extent and kinetics of thermal embrittlement of cast stainless steels from material information that can be determined from the certified material test record. The extent of embrittlement is characterized by the room-temperature "normalized" Charpy-impact energy. Based on the information available, two methods are presented for estimating the extent of embrittlement at "saturation," i.e., the minimum impact energy that would be achieved for the material after long-term aging. The first method utilizes only the chemical composition of the steel. The second method is used when metallographic information on the ferrite morphology, i.e., ferrite content and mean ferrite spacing of the steel, is also available. The change in Charpy-impact energy as a function of time and temperature of reactor service is then estimated from the extent of embrittlement at saturation and from the correlations describing the kinetics of embrittlement, which is expressed in terms of the chemical composition and aging behavior of the steel at $400^{\circ} \mathrm{C}$.

Chopra, O. K., Argonne National Laboratory, "Long-Term Embrittlement of Cast Duplex Stainless Stecls in LWR Systems. Semiannual Report for April - September 1990," NUREG/CR-4744, Vol. 5, No. 2, U.S. Nuclear Regulatory Commission, Washington, D.C., July 1991.

This progress report summarizes work performed by Argonne National Laboratory on long-term $\mathrm{cm}$ brittlement of cast duplex stainless steels in LWR systems during the six months from April-September 1990. A procedure and corrclations are presented for predicting fracture toughness J-R curves and impact strength of aged cast stainless steels from known material information. Fracture toughness of a specific cast stainless stecl is estimated 
from the extent and kinetics of embrittlement. The extent of embrittlement is characterized by the room-temperature Charpy-impact energy. A correlation for the extent of embrittlement at saturation is given in terms of a material parameter, phi, which is determined from the ferrite morphology and/or chemical composition. Charpy-impact energy as a function of time and temperature of reactor service is estimated from the kinetics of embrittlement, which are determined from chemical composition. The fracture toughness J-R curve for the material is then obtained from correlations between room-temperature Charpy-impact energy and fracture toughness parameters. A "lower-bound" J-R curve for cast stainless steels with unknown chemical composition is also defined for a given material specification and temperature. Mechanical-property degradation suffered by cast stainless steel components from the decommissioned Shippingport reactor has been characterized. The results are used to validate the correlations and benchmark the laboratory studies. Charpy-impact, tensile, and fracture toughness data for materials from the hot-leg shutoff valve and cold-leg check valves and pump volute are presented. The results indicate a modest degree of embrittlement.

Chopra, O. K., Argonne National Laboratory, "Long-Term Embrittlement of Cast Duplex Stainless Steels in LWR Systems. Semiannual Report for October 1990 - March 1991," NUREG/CR-4744, Vol. 6, No. 1, U.S. Nuclear Regulatory Commission, Washington, D.C., August 1992.

This progress report summarizes work performed by Argonne National Laboratory on long-term thermal embrittlement of cast duplex stainless steels in LWR systems during the six months from October 1990 to March 1991. Charpy-impact, tensile, and fracture toughness data are presented for several heats of cast stainless steel that were aged up to $58,000 \mathrm{~h}$ at temperatures of $290-400^{\circ} \mathrm{C}$. The results indicate that thermal aging increases the tensile stress and decreases the fracture toughness of the materials. In general, CF -3 steels are the least sensitive to thermal aging embrittlement and CF-8M steels are the most sensitive. The increase in flow stress of fully aged cast stainless steels is $\approx 10 \%$ for CF-3 steels and $\approx 20 \%$ for CF-8 and CF-8M steels. The fracture toughness $\mathrm{J}_{\mathrm{Ic}}$ and average tearing modulus for heats that are sensitive to thermal aging (e.g. CF-8M steels) are as low as $\approx 90 \mathrm{~kJ} / \mathrm{m}^{2}$ and $\approx 60$, respectively.

Chopra, O. K., Argonne National Laboratory, "Long-Term Embrittlement of Cast Duplex Stainless Steels in LWR Systems. Semiannual Report for
April - September 1991," NUREG/CR-4744, Vol. 6, No. 2, U.S. Nuclcar Regulatory Commission, Washington, D.C., November 1992.

This progress report summarizes work performed by Argonne National Laboratory on long-term embrittlement of cast duplex stainless steels in LWR systems during the six months from April to September 1991. A procedure and correlations are presented for predicting Charpy-impact ener$\mathrm{gy}$, tensile flow stress, fracture toughness J-R curve, and $\mathrm{J}_{\mathrm{Ic}}$ of aged cast stainless steels from known material information. The "saturation" impact strength and fracture toughness of a specific cast stainless steel, i.e., the minimum value that would be achieved for the material after long-term service, is estimated from the chemical composition of the steel. Mechanical properties as a function of time and temperature of reactor service are estimated from impact energy and flow stress of the unaged material and the kinetics of embrittlement, which are also determined from chemical composition. The $\mathrm{J}_{\mathrm{Ic}}$ values are determined from the estimated $\mathrm{J}-\mathrm{R}$ curve and flow stress. Examples of estimating mechanical properties of cast stainless steel components during reactor service are presented. A common "lower-bound" J-R curve for cast stainless steels of unknown chemical composition is also defined for a given grade of steel, ferrite content, and temperature.

Chopra, O. K., Argonne National Laboratory, "Long-Term Embrittlement of Cast Duplex Stainless Steels in LWR Systems. Semiannual Report for October 1991 - March 1992," NUREG/CR-4744, Vol. 7, No. 1, U.S. Nuclear Regulatory Commission, Washington, D.C., May 1993.

This progress report summarizes work performed by Argonne National Laboratory on long-term thermal embrittlement of cast duplex stainless steels in LWR systems during the six months from October 1991 to March 1992. Charpy-impact, tensile, and fracture toughness J-R curve data are presented for several heats of cast stainless steel that were aged $10,000-58,000 \mathrm{~h}$ at 290,320 , and $350^{\circ} \mathrm{C}$. The results indicate that thermal aging decreases the fracture toughness of cast stainless steels. In general, CF-3 steels are the least sensitive to thermal aging and CF-8M steels are the most sensitive. The values of fracture toughness $\mathrm{J}_{\mathrm{Ic}}$ and tearing modulus for CF-8M steels can be as low as $\approx 90 \mathrm{~kJ} / \mathrm{m}^{2}$ and $\approx 60$, respectively. The fracture toughness data are consistent with the Charpy-impact results, i.e., unaged and aged steels that show low impact energy also exhibit lower fracture toughness. All steels reach a minimum saturation fracture toughness after thermal 
aging; the time to reach saturation depends on the aging tempcrature. The results also indicate that low-strength cast stainless steels are generally insensitive to thermal aging.

Chopra, O. K., Argonne National Laboratory. "Long-Term Embrittlement of Cast Duplex Stainless Steels in LWR Systems. Semiannual Report for April-September 1992," NUREG/CR-4744, Vol. 7, No. 2, U.S. Nuclear Regulatory Commission, Washington, D.C., July 1993.

This progress report summarizes work performed by Argonne National Laboratory on long-term thermal embrittlement of cast duplex stainless steels in LWR systems during the six months from April-September 1992. A procedure and correlations are presented for predicting Charpy-impact energy tensile flow stress, fracture toughness J-R curves, tearing modulus and $\mathrm{J}_{\mathrm{Ic}}$ of aged cast stain- less steels from known matcrial information. The "saturation" impact strength and fracture toughness of a specific cast stainless steel, i.c., the minimum value that would be achieved for the material after long-term service, is estimated from the chemical composition of the stecl. Mechanical properties as a function of time and $t \mathrm{em}$ perature of reactor service are estimated from impact energy and flow stress of the unaged material and the kinetics of embrittlement, which are also determined from chemical composition. The $\mathrm{J}_{\mathrm{Ic}}$ values are determined from the estimated $\mathrm{J}-\mathrm{R}$ curve and flow stress. Examples of estimating mcchanical properties of cast stainless stecl components during reactor service are presented. A common "lower-bound" J-R curve for cast stainless steels of unknown chemical composition is also defined for a given grade of steel, ferrite content, and temperature. 


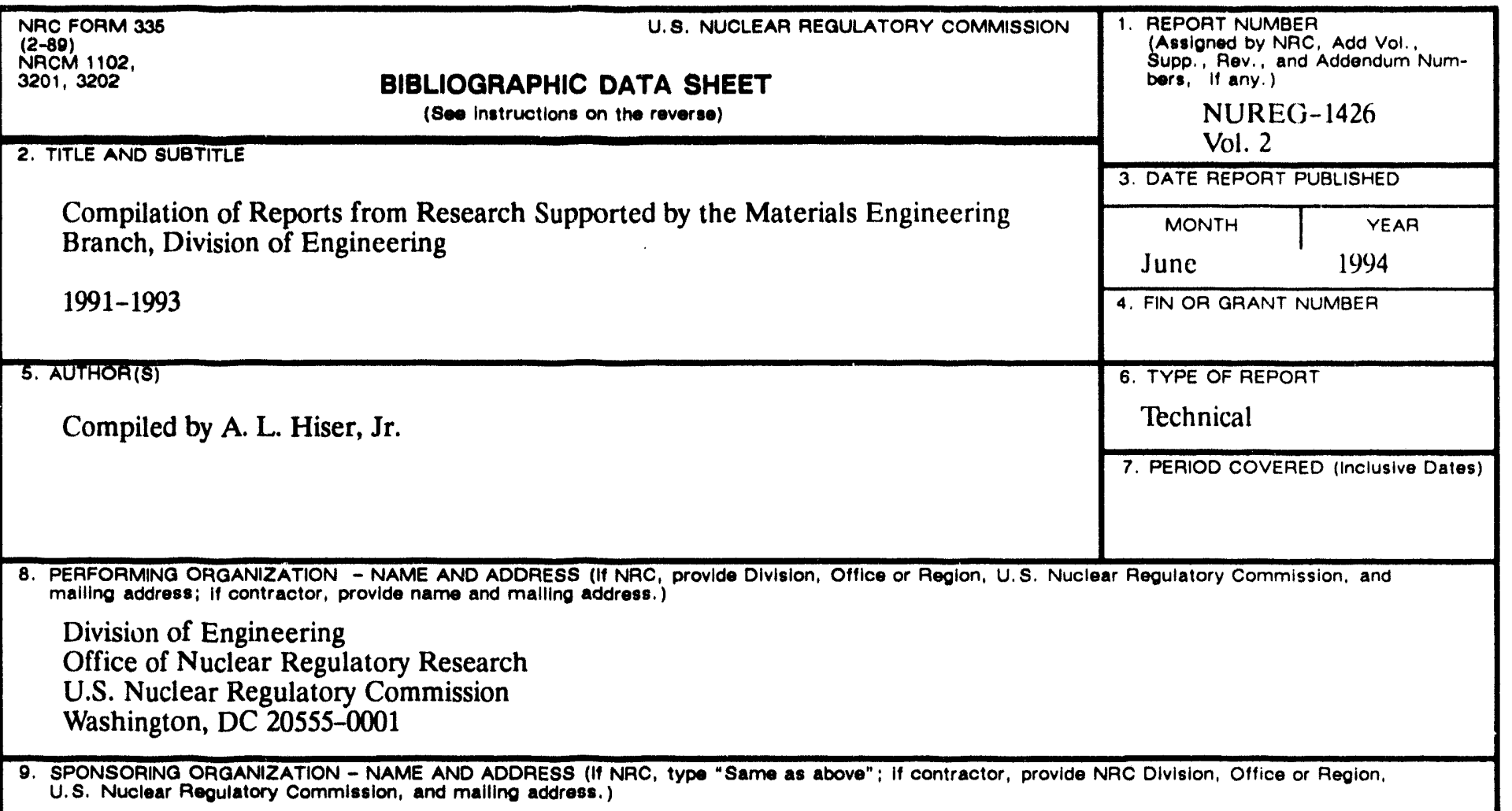

Same as above.

10. SUPPLEMENTARY NOTES

11. ABSTAACT $(200$ words or less)

Since 1965, the Materials Engineering Branch, Division of Engineering, of the Nuclear Regulatory Commission's Office of Nuclear Regulatory Research, and its predecessors dating back to the Atomic Energy Commission (AEC), has sponsored research programs concerning the integrity of the primary system pressure boundary of light water reactors. The components of concern in these research programs have included the reactor pressure vessel (RPV), steam generators, and the piping. These research programs have covered a broad range of topics, including fracture mechanics analysis and experimental work for RPV and piping applications, inspection method development and qualification, and evaluation of irradiation effects to RPV steels.

This report provides as complete a listing as practical of formal technical reports submitted to the NRC by the investigators working on these research programs. This listing includes topical, final and progress reports, and is segmented by topic area. In many cases a report will cover several topics (such as in the case of progress reports of multi-faceted programs), but is listed under only one topic. Therefore, in searching for reports on a specilic topic, other related topic areas should be checked also. The previous volume to this report covers the period $1965-1990$.

12. KEY WORDSIDESCRIPTORS (List words or phrases that will assist researchers in locating the report.)

reactor pressure vessels, piping, fracture mechanics, non-destructive examination, radiation embrittlement, dosimetry, environmentally-assisted cracking, fatigue, steam generators, annealing, research reports

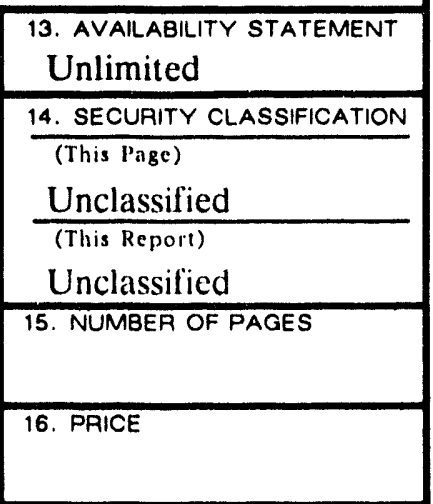



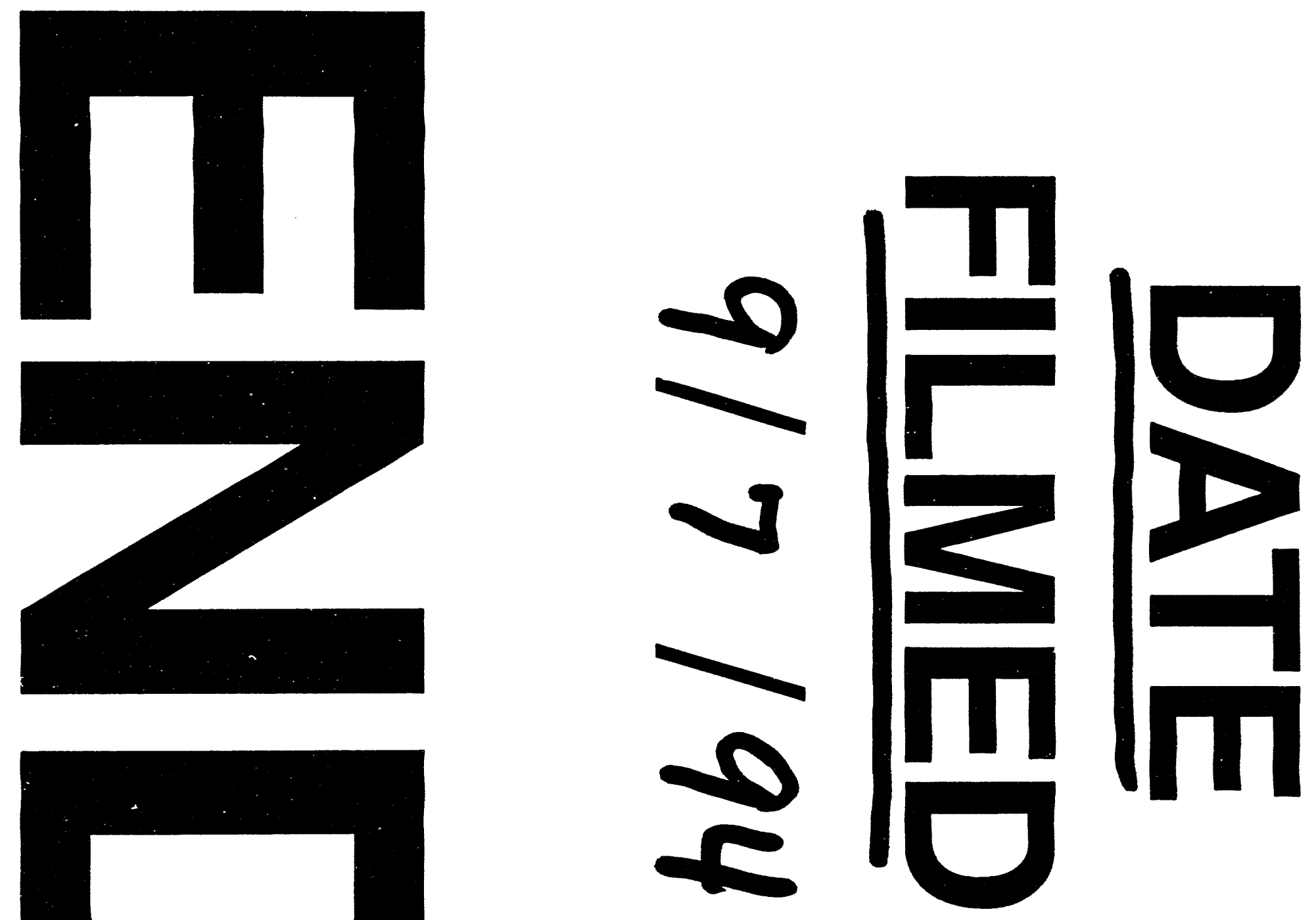
• 